\title{
Active Dentate Granule Cells Encode Experience to Promote the Addition of Adult-Born Hippocampal Neurons
}

\author{
Gregory W. Kirschen, ${ }^{1,2 *}$ Jia Shen, ${ }^{3 *}{ }^{\circledR}$ Mu Tian, ${ }^{4}{ }^{\circledR B}$ Bryce Schroeder, ${ }^{1,5}$ Jia Wang, ${ }^{6}$ Guoming Man, ${ }^{6}$ Song Wu, ${ }^{7}$ \\ and Shaoyu $\mathrm{Ge}^{6}$ \\ ${ }^{1}$ Medical Scientist Training Program, ${ }^{2}$ Molecular and Cellular Pharmacology Program, ${ }^{3}$ Genetics Program, ${ }^{4}$ Applied Mathematics and Statistics Program, \\ ${ }^{5}$ Department of Biomedical Engineering, ${ }^{6}$ Department of Neurobiology and Behavior, and ${ }^{7}$ Department of Applied Mathematics and Statistics, \\ State University of New York, Stony Brook, New York 11794
}

The continuous addition of new dentate granule cells (DGCs), which is regulated exquisitely by brain activity, renders the hippocampus plastic. However, how neural circuits encode experiences to affect the addition of adult-born neurons remains unknown. Here, we used endoscopic $\mathrm{Ca}^{2+}$ imaging to track the real-time activity of individual DGCs in freely behaving mice. For the first time, we found that active DGCs responded to a novel experience by increasing their $\mathrm{Ca}^{2+}$ event frequency preferentially. This elevated activity, which we found to be associated with object exploration, returned to baseline by $1 \mathrm{~h}$ in the same environment, but could be dishabituated via introduction to a novel environment. To transition seamlessly between environments, we next established a freely controllable virtual reality system for unrestrained mice. We again observed increased firing of active neurons in a virtual enriched environment. Interestingly, multiple novel virtual experiences increased the number of newborn neurons accumulatively compared with a single experience. Finally, optogenetic silencing of existing DGCs during novel environmental exploration perturbed experience-induced neuronal addition. Our study shows that the adult brain conveys novel, enriched experiences to increase the addition of adult-born hippocampal neurons by increasing the firing of active DGCs.

Key words: dentate granule cell; enriched environment; hippocampal neurogenesis; novel experience; virtual reality

\section{Significance Statement}

Adult brains are constantly reshaping themselves from synapses to circuits as we encounter novel experiences from moment to moment. Importantly, this reshaping includes the addition of newborn hippocampal neurons. However, it remains largely unknown how our circuits encode experience-induced brain activity to govern the addition of new hippocampal neurons. By coupling in vivo $\mathrm{Ca}^{2+}$ imaging $^{2}$ of dentate granule neurons with a novel, unrestrained virtual reality system for rodents, we discovered that a new experience increased firing of active dentate granule neurons rapidly and robustly. Exploration in multiple novel virtual environments, compared with a single environment, promoted dentate activation and enhanced the addition of new hippocampal neurons accumulatively. Finally, silencing this activation optogenetically during novel experiences perturbed experience-induced neuronal addition.

\section{Introduction}

The hippocampus confers robust plasticity to the adult brain with the continuous addition of new neurons throughout life (Altman and Das, 1965; Kempermann et al., 1997; Gould et al., 1999;

Received Nov. 3, 2016; revised March 1, 2017; accepted March 5, 2017.

Author contributions: G.W.K., J.S., and S.G. designed research; G.W.K., J.S., B.S., and G.M. performed research; B.S. and J.W. contributed unpublished reagents/analytic tools; G.W.K., J.S., M.T., and S.W. analyzed data; G.W.K., J.S., and S.G. wrote the paper.

This work was supported by the National Institutes of Health (Grants AG046875 and NS089770 to S.G. and Grant 1F30MH110103 to G.W.K.). We thank Walter Schmeling and Jeff Slechta of the University Machine Shop for assistance with the design and execution of the VR system; Jason Wu for assistance with experimental procedures; and René Hen, Lorna Role, Grigori Enikolopov, Ramin Parsey, Amar Sahay, Il-Memming Park, Yan Gu, Michael Frohman, John Robinson, and Qiaojie Xiong for valuable feedback on this work.

The authors declare no competing financial interests.

${ }^{*}$ G.W.K. and J.S. contributed equally to this work.
Nilsson et al., 1999; Cameron and McKay, 2001; Temprana et al., 2015). New hippocampal neurons are born daily, and synaptically integrate into the existing dentate granule cell (DGC) circuit (Zhao et al., 2008). The integrated new neurons not only rejuvenate the existing circuit, but also affect hippocampus-related behavior directly (Ge et al., 2006; Gu et al., 2013; Kirschen et al., 2016). Interestingly, an increase in the number of new hippocampal neurons added within a given period is reflected in a benefit to complex, hippocampus-based behaviors (Sahay et al., 2011a). The question that remains to date is how the adult brain is able to

Correspondence should be addressed to Dr. Shaoyu Ge, Department of Neurobiology and Behavior, Life Sciences Building, Rm. 564, SUNY Stony Brook, Stony Brook, NY 11794. E-mail: shaoyu.ge@stonybrook.edu. D0I:10.1523/JNEUROSCI.3417-16.2017

Copyright $\odot 2017$ the authors $\quad 0270-6474 / 17 / 374661-18 \$ 15.00 / 0$ 
control the number of new neurons to be added into its circuits in a given period.

Mounting evidence suggests that brain activity regulates the number of newborn neurons, likely through three strategies: (1) control of the pool size of available newborn neurons via proliferation and differentiation of neural progenitors, (2) the survival rate of newborn neurons, and (3) their functional integration. Hippocampus-guided exploration enhances the circuit integration of newborn DGCs while promoting the activation of the trisynaptic circuit (Kempermann et al., 1997; Kee et al., 2007; Tashiro et al., 2007; Freund et al., 2015). This regulation may arise from enhancing the activity of the DGC circuit to regulate the pool of new neurons. One study showed that acute electrical stimulation of the perforant pathway increases the proliferation of progenitors (Stone et al., 2011) or by activating local interneuron circuits, which promotes the survival of newborn DGCs (Song et al., 2013). Other recent investigations have shown that hippocampal-based behaviors may rewire local interneuron connections converging onto DGCs to regulate hippocampal neurogenesis (Bergami et al., 2015; Temprana et al., 2015; Alvarez et al., 2016). However, it remains to be tested whether such stimulation promoting enhanced neurogenesis was propagated through excitatory circuits. Together, these observations led us to speculate that the existing excitatory DG circuitry may be the key regulator controlling the quantity of new hippocampal neurons to be added within a given period.

The plausibility of this speculation has also been revealed when the normal progression of adult neurogenesis becomes disrupted. For example, epileptiform discharge, which activates the DG circuit tonically, increases progenitor cell proliferation acutely, but exhausts neurogenesis chronically by depleting the progenitor pool and inducing aberrant connectivity among newborn DGCs (Scharfman et al., 2000; Madsen et al., 2003; Jakubs et al., 2006; Parent et al., 2006; Hsieh and Schneider, 2013; Sierra et al., 2015). If the local DGC circuit controls the rate of addition of new hippocampal neurons, we thus wondered how the DGC circuit encodes hippocampal-based activity to execute this regulation.

In this study, we set out to determine how the adult brain encodes its circuits' activity to affect the number of new neurons to be added to the hippocampus. We established an in vivo $\mathrm{Ca}^{2+}$ imaging method to monitor the activity of individual hippocampal cells in freely moving rodents. We found that environmental exploration enhanced the circuit activity of the DG by increasing the firing rate of active DGCs. We further found that this increased firing in an enriched (Enr) environment lasted only across the first several minutes of exploration, with rapid subsequent habituation that could be dishabituated by introducing a novel environment. Using a novel virtual reality (VR) system that we developed to present an array of novel environments seamlessly, we observed an increase in the number of newborn DGCs and heightened circuit activity in virtual Enr environments. An additional analysis showed that this heightened activity was associated with object exploration. Finally, we used an optogenetic approach to silence this activity and found that silencing DGCs during exploration abolished the experience-related increase in the addition of newborn hippocampal neurons.

\section{Materials and Methods}

Surgeries and procedures

All surgeries and experimental procedures were approved by the Stony Brook University Animal Use Committee and followed the guidelines of the National Institutes of Health.
Mice

Experiments were conducted using 6- to 8-week-old C57BL/6 mice (Charles River Laboratories). Each dataset included both male and female animals because previous work has shown no detectable sex differences in adult hippocampal neurogenesis (Lagace et al., 2007; Ben Abdallah et al., 2010). All mice were housed in pairs and maintained on a $12 \mathrm{~h}$ light/dark cycle. All behavioral experiments were performed during the light cycle. Mice were provided ad libitum access to food and water except during treadmill training and navigation testing, during which time they were water deprived overnight.

\section{Viruses}

Retrovirus and lentivirus production was performed as we described previously (Gu et al., 2012). Adeno-associated virus 9 (AAV9)-calmodulin protein kinase II (CaMKII)-GCaMP6f was purchased from the University of Pennsylvania Vector Core and AAV-CaMKII-GFP and AAV-CaMKIIhalorhodopsin (Halo) were purchased from the University of North Carolina Vector Core.

\section{Deep-brain calcium imaging and data processing}

For $\mathrm{Ca}^{2+}$ imaging in freely moving mice, we injected AAV9-CaMKIIGCaMP6f virus (University of Pennsylvania Vector Core) in the dorsal DG (given the critical role of the dorsal hippocampus in spatial navigation (Moser and Moser, 1998; Hampson et al., 1999) as we described previously ( $\mathrm{Gu}$ et al., 2012) after lens probe (outer diameter $=1.0 \mathrm{~mm}$, length $=4.0 \mathrm{~mm}$, numerical aperture $=0.5)$ and baseplate implantation. The lens was implanted $0.2-0.3 \mathrm{~mm}$ superior to the viral injection site. Four to 6 weeks after viral injection, $\mathrm{Ca}^{2+}$ signals were imaged during exposure to Enr and standard (Std) environments for 2 consecutive days. $\mathrm{Ca}^{2+}$ imaging was recorded with a miniaturized video microscope recording at a frame rate of $20 \mathrm{~Hz}$ (Inscopix). We recorded from each animal for 5 min per environment per day, with a 5 min rest period in the animal's home cage between the two environments. The order of Std and Enr environments was counterbalanced on the second day of imaging. All videos were processed in Mosaic software (Inscopix). Videos taken from the same animal exposed to the two environments on the same day were concatenated and motion corrected. Then, active cells were detected by a combined principle component-independent component analysis algorithm (Mukamel et al., 2009) with 0.1 weight of temporal information. Individual cells detected by the algorithm were screened manually from each concatenated video. Only cells with clearly identified signals were included in analyses. Calcium events were identified by a criterion of $>8 \times$ the median absolute deviation and $>0.2 \mathrm{~s}$ tau-off with the input normalized $\Delta F / F$ signal at its local maximum. Locomotion normalization was performed by dividing the $\mathrm{Ca}^{2+}$ event rate for each cell by the total distance covered by the animal during the recording period.

Changes in the $z$-axis are associated with a rotation in the microscope's field of view (i.e., rotation of the sensor turret). The position of the turret was fixed by a screw before all imaging sessions and, because we observed no rotation of field of view, this indicated no change in the $z$-axis. $\mathrm{Mi}$ cromotion of brain tissue in the $x$ - and $y$-axes was corrected by using blood vessels as anatomical landmarks to calibrate the alignment over the course of imaging.

To measure the relative $\mathrm{Ca}^{2+}$ influx amount, we computed the area under the curve (AUC) value using the following approach. For each detected event, we located its left and right cutoff time points and computed the area under the trace signal curve. The area was calculated as the sum of all pieces of a trapezoidal segment along each consecutive time point (trapezoidal rule for integration). The final AUC value was determined for each recorded period as the sum of all events' AUCs divided by length of time. The left/right cutoff time points for each event were determined as follows: starting from the time point for the event, the first non-negative local minimum was defined as the left cutoff time point and the last non-negative local minimum was defined as the right cutoff time point.

For simultaneous $\mathrm{Ca}^{2+}$-imaging and exploratory behavior analyses, time-stamped $\mathrm{Ca}^{2+}$ imaging videos were coupled to EthoVision XT videos tracking animal trajectories. $\mathrm{Ca}^{2+}$ transients were correlated with animal position in Matlab (The MathWorks) for each individual neuron. The pixel with the peak firing rate was found and smoothed with kernel 
density estimation. Firing fields were defined as areas in which the normalized $\mathrm{Ca}^{2+}$ event rate exceeded $50 \%$ of the peak rate (Miao et al., 2015). Individual neurons were compared with themselves between the same or different Enr environments. Only cells exhibiting firing fields in at least two conditions were analyzed. Firing field remapping was calculated for each cell (within-cell analysis) according to the root mean square deviation as follows:

$$
d=\sqrt[V]{ }\left(\left[X_{2}-X_{1}\right]^{2}+\left[Y_{2}-Y_{1}\right]^{2}\right)
$$

Where $d$ is the distance between firing fields' peak event rate loci, $X_{1}$ and $Y_{1}$ are the coordinates of the peak event rate locus in the first environment, and $\mathrm{X}_{2}$ and $Y_{2}$ are the coordinates of the peak event rate locus in the second environment.

\section{Behavioral apparatuses and procedures}

VR system. The VR system consisted of a dual desktop running Ubuntu Desktop 14.04 LTS. Two optical mice controlled the computer: the experimenter's was externally accessible, whereas that used for detection of the animal's movement was located on the underside of a $20.3 \mathrm{~cm}$ Styrofoam spherical treadmill, with $1-2 \mathrm{~mm}$ clearance from the treadmill. The VR cage consisted of a $30 \times 18 \times 13 \mathrm{~cm}^{3}$ Plexiglas box with a centered 14-cm-diameter circular hole on the floor, which was aligned with the top of the treadmill. A seven-bladed fan was used to airlift the treadmill. Fan speed was adjusted via a solid-state speed controller to calibrate for varying animal weights. Custom Python scripts were used to control avatar movement in the virtual environment as well as to track distance and trajectory. Trajectory data were analyzed after acquisition using iPython Notebook.

Water reward delivery system. Virtual environment software (implemented in the Python programming language environment provided by Blender Game Engine) was programmed to detect the presence of the animal in a user-designated target zone via a collision detection mechanism between a virtual trip wire and the virtual avatar. Upon entry into the target zone, the controller computer was signaled via a direct ethernet connection. The controller used an Arduino open-source microcontroller development board to open and close MOSFET-controlled solenoid pinch valves. The solenoid valves allowed a liquid reward to flow by gravity through a small-diameter silicone tube connected to a metal feeding tube situated directly over the treadmill. The controller provides a web-based system for adjusting the duration of the valve opening and the delay. Reward delivery could also be manually controlled by the user through keyboard buttons designated in the Blender Game Engine to trigger running of the valve opening/closing script.

$V R$ behavioral training and testing protocol. Animals were handled twice daily for $3 \mathrm{~d}$ before the start of all behavioral experiments. Mice were assigned randomly to exposure conditions. During operant conditioning (10 d training), water bottles were withdrawn overnight to induce a motivational state of thirst. Sixteen to $18 \mathrm{~h}$ after overnight water deprivation, mice were returned to the VR cage for $1 \mathrm{~h}$ daily during the subsequent $10 \mathrm{~d}$ and running behavior was shaped with $20 \mu \mathrm{l}$ water droplet rewards delivered electronically via overhead feeding tube.

The navigation task consisted of a $5 \mathrm{~d}$ learning period during which water-deprived mice that had learned successfully to run on the treadmill were exposed to a $1 \mathrm{~m}^{2}$ virtual environment with background walls and objects to serve as spatial cues. Each training session consisted of $1 \mathrm{~h}$ during which the mouse was free to run on the treadmill and would receive a reward automatically upon entering the reward zone (trained condition) or at randomly determined intervals throughout the training period (untrained condition). Navigation probe testing occurred over the subsequent $3 \mathrm{~d}$, during which time reward, distance, and location data were recorded over a $30 \mathrm{~min}$ trial period. Latency to enter the target zone was recorded. Intercondition analysis was conducted by calculating $Z$ scores as follows: reward-location-binned zone - average-locationbinned zone/SD of location-binned zone. For intracondition analysis of the virtual navigation task, $Z$ scores were computed for the four corners of the virtual arena (one of which was the reward zone), as described above. Heat maps were generated from location counts grouped into 400 total bins using iPython Notebook.

Virtual Enr and Std environments. Mice were assigned randomly to a virtual environment exposure condition and then trained to run volun- tarily on the treadmill (as above) in their respective environments. They then received $1.5 \mathrm{~h} / \mathrm{d}$ of virtual environmental exposure for 2 or 12 consecutive days, with a single BrdU injection administered on day 1 (10 $\mu \mathrm{g} / \mathrm{g}$, i.p.). In the Enr condition, background, floor pattern, and virtual objects were rotated daily. Environmental conditions remained constant in the control condition (single floor pattern, no background images or objects). For multiple enrichment experiments, mice were exposed to two daily 45 min intervals of randomly selected virtual Enr environments for 12 consecutive days, with a single BrdU injection $(10 \mu \mathrm{g} / \mathrm{g}$, i.p.) or lineage tracer viruses (lenti-GFAP-Cre + retro-double-floxed (DF)reGFP coinfusion into the DG, $0.5 \mu \mathrm{l} /$ injection site, stereotactic coordinates $-2.0 \mathrm{~mm}$ from bregma, $\pm 1.6 \mathrm{~mm}$ lateral, and $-3.0 \mathrm{~mm}$ from bregma, $\pm 2.6 \mathrm{~mm}$ lateral).

Real Enr and Std environments. Mice were assigned randomly to either Enr $\left(1 \mathrm{~m}^{3}\right)$ or Std $\left(1 \mathrm{~m}^{3}\right)$ environmental conditions and placed in their respective exposure conditions for $1.5 \mathrm{~h}$ daily for 12 consecutive days, with a single $\mathrm{BrdU}$ injection administered on day $1(10 \mu \mathrm{g} / \mathrm{g}$, i.p.) or lineage tracer viruses. The Enr environment consisted of five to $10 \mathrm{ob}-$ jects, including tunnels, toys, and geometrical blocks, similar to those used in previous studies (Hosseiny et al., 2015; Alvarez et al., 2016). Objects and object locations in the Enr condition were rotated daily to provide novelty and encourage exploration (Grégoire et al., 2014). Importantly, the Enr cage lacked a running wheel to keep locomotion comparable between groups. The Std cage contained only floor bedding. After exposure, mice were returned to their home cages.

$c$-Fos. We quantified cells that immunostained positive for the protein product of the immediate early gene $c$-fos, as described previously (Kee et al., 2007; Xiu et al., 2014). Mice were exposed to their assigned environment and allowed to explore freely for $90 \mathrm{~min}$. For virtual exposures, mice were permitted to explore freely until reaching $45 \mathrm{~m}$, at which point the treadmill was locked to keep locomotion approximately equal between groups. Mice were then returned to their home cages for an additional $45 \mathrm{~min}$ to allow adequate time for c-Fos protein expression and then killed via transcardiac perfusion. Heat maps were generated in Matlab using the relative fold changes in c-Fos counts between conditions.

Object exploration test. We performed an object exploration test similar to what we have described previously (Rhee et al., 2016). The procedure for calcium-imaging experiments was performed as follows. On day 1 , mice were habituated to a $1 \mathrm{~m}^{3}$ Std arena lacking objects for $10 \mathrm{~min}$. On day 2, mice were placed in the same arena lacking objects for $5 \mathrm{~min}$, returned to their home cages for $5 \mathrm{~min}$, and then placed back in the arena containing 4 distinct objects (Enr 1) and allowed to explore for $5 \mathrm{~min}$ (environment order counterbalanced). On day 3 , mice were again placed in the Std arena for $5 \mathrm{~min}$ and Enr 1 for $5 \mathrm{~min}$, followed by 5 min resting time in the home cage, and were then placed back in Enr 1. After another $5 \mathrm{~min}$ of rest in the home cage, animals were exposed to another distinctive environment, Enr 2, for 5 min. The objects in Enr 2 were different from those in Enr 1, but the combined area encompassed by the objects was nearly identical between environments (Enr 1: $350.6 \mathrm{~cm}^{2}$, Enr2: $343.5 \mathrm{~cm}^{2}$; total arena $=1080 \mathrm{~cm}^{2}$ for both). Exposure order was counterbalanced. Object location zones were predefined as $2.0 \mathrm{~cm}$ radii around each object and animal paths were recorded using EthoVision XT video-tracking software. Animal orientation within object zones was not analyzed. The procedure for optogenetics experiments was similar with the following exceptions. Animals were allowed to explore only Enr 1 on day 2 and only Enr 2 on day 3 for $10 \mathrm{~min}$, during which time orange light was pulsed at $1 \mathrm{~Hz}$.

\section{Optogenetics}

Mice were assigned randomly to either real Enr or Std environment exposure, as described above, and received bilateral intrahippocampal injections of either AAV-CaMKII-GFP or AAV-CaMKII-Halo $(0.5 \mu \mathrm{l} /$ injection site, stereotactic coordinates $-2.0 \mathrm{~mm}$ from bregma, $\pm 1.6 \mathrm{~mm}$ lateral, and $-3.0 \mathrm{~mm}$ from bregma, $\pm 2.6 \mathrm{~mm}$ lateral). Mice were injected with the AAV vector and implanted with an optrode head mount at the anterior (dorsal DG) coordinate and then allowed 2 weeks to recover from surgery and for channel protein expression. Mice were then exposed to their respective conditions as described above for 12 consecutive days $(2 \mathrm{~h} / \mathrm{d}$ or $25 \mathrm{~min} / \mathrm{d}$ ), during which time they received orange 
light pulsed at $1 \mathrm{~Hz}$, as we described previously (Song et al., 2012). On day 15 , all mice received a single injection of $\operatorname{BrdU}(10 \mu \mathrm{g} / \mathrm{g}$, i.p. $)$. Mice were killed on day 26.

\section{Tissue processing, imaging, and quantification}

Mice were deeply anesthetized with urethane $(200 \mu \mathrm{g} / \mathrm{g})$ and perfused transcardially with PBS and then 4\% PFA. Brains were removed, fixed overnight in $4 \% \mathrm{PFA}$, transferred to a $30 \%(\mathrm{w} / \mathrm{v})$ sucrose solution, and stored at $4^{\circ} \mathrm{C}$ until sectioning. Brains were sectioned into $60 \mu \mathrm{m}$ coronal sections (for BrdU and c-Fos experiments) and $80 \mu \mathrm{m}$ coronal sections (for lineage tracing experiments, to guard against disrupting cell clusters) covering the entire anterior-posterior axis of the DG. Immunohistochemistry was performed by blocking sections in $1 \%$ donkey serum in PBS $+0.025 \%$ Triton for $1 \mathrm{~h}$ at room temperature (after incubation in $2 \mathrm{~N}$ $\mathrm{HCl}$ for $25 \mathrm{~min}$ at $37^{\circ} \mathrm{C}$ for BrdU only) and then switched to incubation in primary antibody, BrdU (rat polyclonal antibody, 1:1000; Calbiochem), GFP (rabbit polyclonal antibody, 1:1000; Sigma-Aldrich), c-Fos (goat polyclonal, 1:1000; Santa Cruz Biotechnology) with overnight shaking at $4^{\circ} \mathrm{C}$. Sections were then switched to secondary antibody, Alexa Fluor 488-conjugated donkey anti-rat antibody (1:1000; Abcam), Alexa Fluor 594-conjugated donkey anti-rat antibody (1:1000; Abcam), Alexa Fluor 488-conjugated donkey anti-rabbit antibody (1:1000; Jackson Laboratories), and Alexa Fluor 488-conjugated donkey anti-goat (1:1000, Abcam) for $3 \mathrm{~h}$ shaking at room temperature.

Images were obtained on an Olympus FLV1000 confocal microscope. We used every fourth brain section and counted fluorescently labeled cells within the granule cell layer (GCL) and subgranular zone of the DG for half of the brain across the entire anterior-posterior axis of the DG. We then multiplied this number by two to arrive at an approximation for total number of labeled cells/DG, as described previously (Gould et al., 1999; Cameron and McKay, 2001). For optogenetic experiments, we excluded BrdU + cells found within $200 \mu \mathrm{m}$ of the injection track to avoid inclusion of the injection site. For lineage-tracing analysis, we defined clusters as cells within a $200 \mu \mathrm{m}$ tangential radius (at least $400 \mu \mathrm{m}$ away from an adjacent cluster), also excluding cell clusters found within $200 \mu \mathrm{m}$ of the injection track to avoid inclusion of the injection site (Sun et al., 2015).

We counted c-Fos + cells in the GCL and subgranular zone of the DG. Images were obtained on a Yokogawa CV1000 spinning disc confocal microscope and analyzed using Cell Voyager CV1000 software. We used a stereological unbiased random sampling approach of $60 \mu \mathrm{m} Z$-stacked images ( $175 \mu \mathrm{m} \times 175 \mu \mathrm{m}$ in $x$ and $y$ planes) with $2 \mu \mathrm{m}$ guard zones, similar to what has been described previously (Kleim et al., 1996; Guzowski et al., 1999).

\section{Statistical analyses}

Data were analyzed with independent- and paired-samples $t$ tests, oneway ANOVA followed by post hoc Dunnett's 2-tailed $t$ test or least significant difference test, one-way ANOVA with repeated measures followed by post hoc paired $t$ tests, the Kolmogorov-Smirnov test, and the likelihood ratio test on multinomial distributions. Two-tailed values of $\alpha<$ 0.05 were considered the cutoff for statistical significance. All data are represented as mean \pm SEM. $n$ represents the number of animals unless otherwise specified.

\section{Results \\ Environmental exploration promotes the firing of active DGCs preferentially}

To determine how the adult hippocampal circuit encodes its activity to affect the number of new DGCs to be added into its circuits in a given period, we first mapped the activity of neural networks responding to a novel Enr environment, which is well known to promote the addition of new hippocampal neurons (Kempermann et al., 1997; Brown et al., 2003). As illustrated in Figure 1A, two groups of mice were exposed to either an Enr or Std environment for $90 \mathrm{~min}$ and then returned to their home cages. Forty-five minutes later, we performed a post hoc analysis of the protein product of the immediate early gene $c$-fos in differ- ent brain areas, reflecting accumulative brain activity during this period (Kleim et al., 1996; Xiu et al., 2014). As expected, the novel environmental exposure drove robust $c$-fos expression in the hippocampal trisynaptic circuitry (Fig. $1 A$ ), which is involved in spatial information processing (Aimone et al., 2011). This activation led us to speculate that existing DGCs, the direct recipients of input into the trisynaptic circuit, may indeed encode exploratory activity directly to affect the addition of new hippocampal neurons.

To investigate how existing DGCs act in an Enr environment in real time, we established a deep-brain-imaging method to monitor neuronal activity in freely moving animals. As diagrammed in Figure $1 B$, we expressed GCaMP6f, an efficient sensor to detect $\mathrm{Ca}^{2+}$ transients (Chen et al., 2013b), in DGCs with an AAV under the control of the $\mathrm{Ca}^{2+} / \mathrm{CaMKII}$ promoter. The activity of DGCs was monitored by detecting $\mathrm{Ca}^{2+}$-induced fluorescence transients with a miniaturized microscope (Ghosh et al., 2011).

We tested how a novel Enr experience would affect DGC activity by exposing mice to either an Enr or a Std environment (exposure order counterbalanced in these tests) and recording $\mathrm{Ca}^{2+}$ transients for $5 \mathrm{~min}$ (Fig. $1 \mathrm{~B}, C$ ). Correct lens positioning and successful targeting of AAV-CaMKII-GCaMP6f to DGCs of these mice were confirmed by histological examination after all tests (Fig. $1 B$, bottom left). We performed a post hoc quantification of the number of GCaMP6f + cells from a single-scanned horizontal DG section and found that $\sim 533$ GCaMP $6 f+$ cells could be identified in the lens' field of view (Fig. $1 B$, top right). In these behavioral tests, we observed substantially more $\mathrm{Ca}^{2+}$ events upon exposure to the Enr environment (Fig. $1 C, D ; n=577$ neurons from 5 animals; see Movie 1 for representative recording). This was indeed the case when we compared the distribution of $\mathrm{Ca}^{2+}$ event rates in the two environments for each individual recorded cell. We observed a significantly elevated shift in the distribution of event rates in the Enr condition (Fig. 1D, inset, Kolmogorov-Smirnov test, $p<0.001)$. This suggests an increase in the firing rate of most, if not all, recorded cells. We therefore investigated whether every recorded DGC increased its firing in the Enr environment. As shown in Figure 1, D-F, the majority of cells increased their event frequency in the Enr environment, whereas a minority of cells actually either decreased or exhibited no change in firing between the two environments.

To determine whether the increased $\mathrm{Ca}^{2+}$ transient frequency was also accompanied by more $\mathrm{Ca}^{2+}$ influx for each event, we computed the AUC of the $\mathrm{Ca}^{2+}$ event peaks, which takes into account $\mathrm{Ca}^{2+}$ transient amplitude and duration, under Std and Enr conditions. Notably, there was a significantly elevated shift in the AUC distribution in the Enr condition (Fig. 1G, KolmogorovSmirnov test, $p<0.001)$. We also investigated whether the increased activity in the Enr condition was also reflected in the activation of more DGCs. We counted the total number of cells that had exhibited at least one $\mathrm{Ca}^{2+}$ transient under each condition. Interestingly, we found that almost all active cells exhibited events in both environments, with a slight albeit not statistically significant increase in the number of active cells in the Enr environment (Fig. $1 H$, 2-tailed paired $t$ test, $p=0.052$ ). Note that the number of active cells (Fig. $1 H$ ), together with the total number of GCaMP6f-labeled cells (Fig. $1 B$ ), suggests that only $\sim 8.99 \%$ and $9.47 \%$ of the GCaMP6f+ cells fired during recording sessions in the Std and Enr environments, respectively, consistent with a sparsely active neuronal population (Danielson et al., 2016; Pilz et al., 2016). To exclude the potential contribution of locomotion to the increased transient frequency of active cells, we normalized the transient frequency to distance traveled in the environments and observed a similar significant increase to that 
A
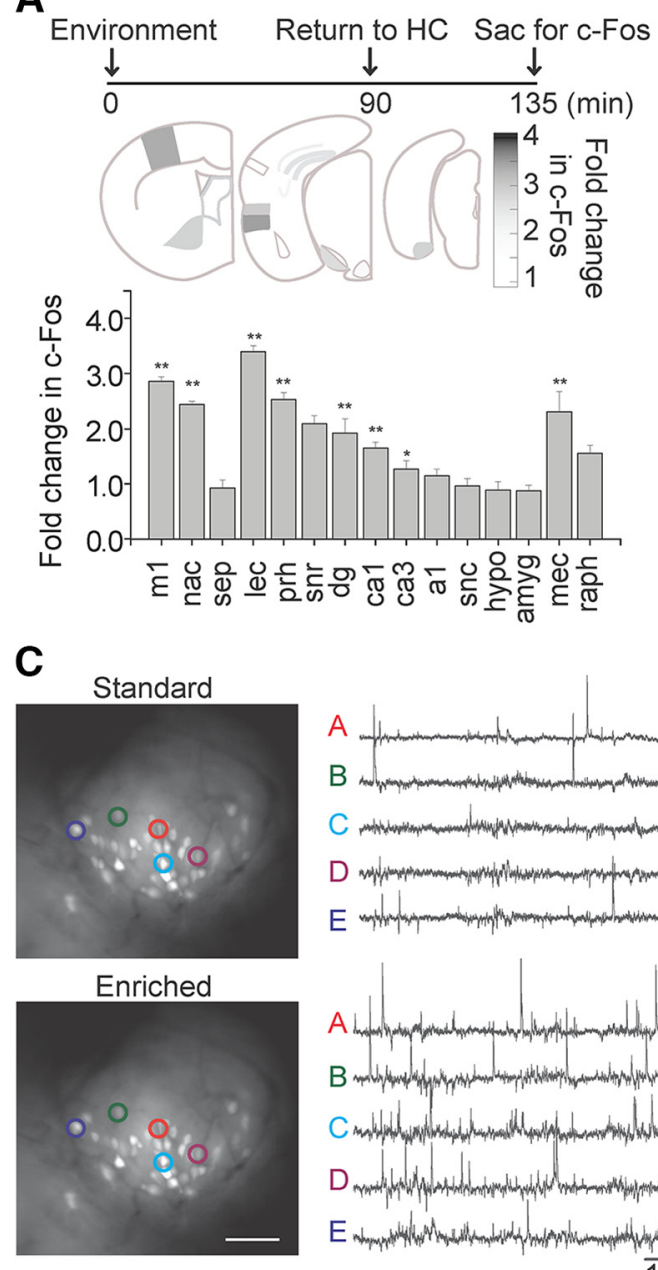

E
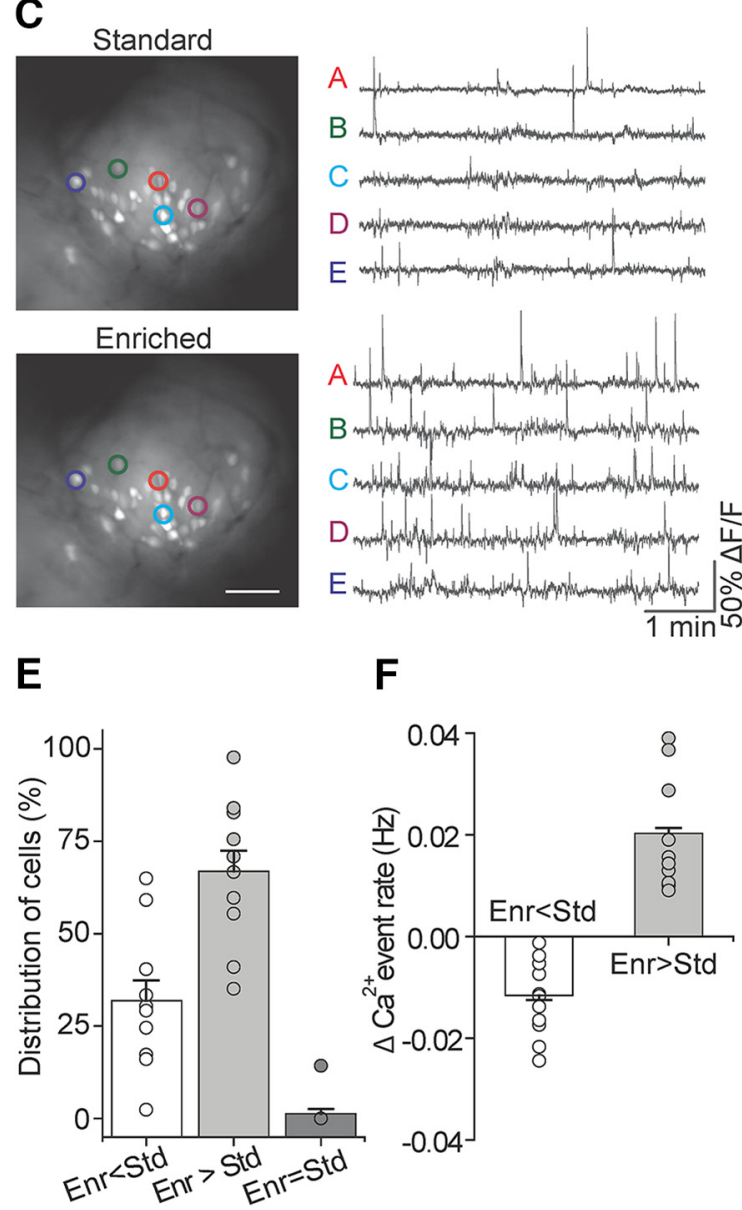

B
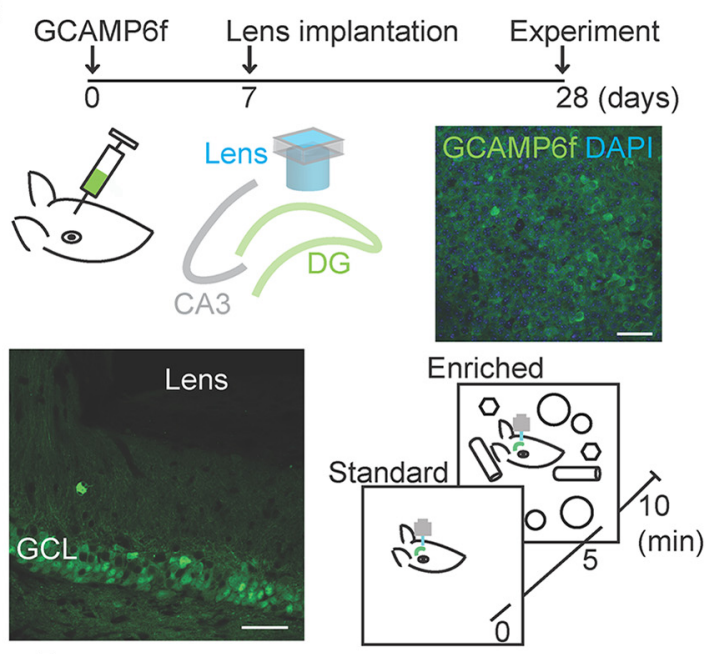

D

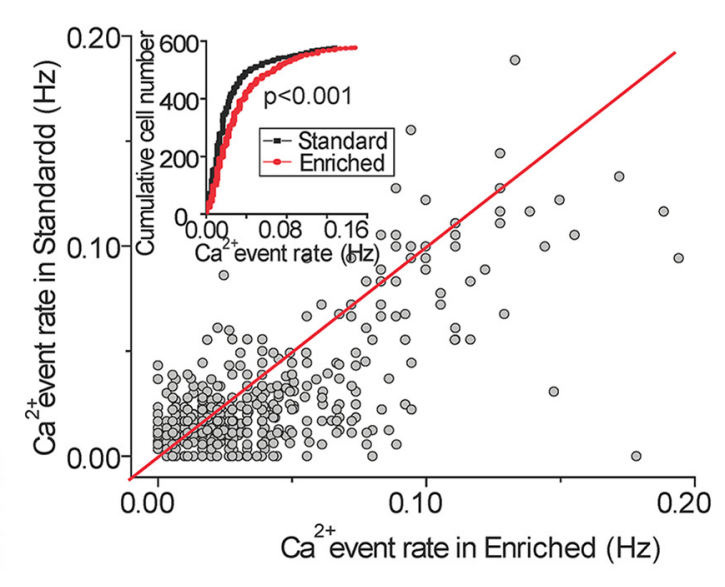

G

H
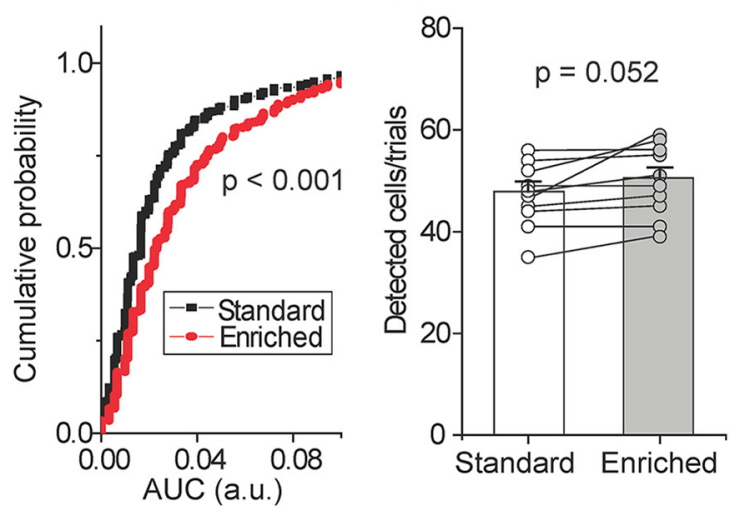

Figure 1. Environmental enrichment increases the $\mathrm{Ca}^{2+}$ transient frequency of active DGCs. A, Mapping brain circuit activity in an Enr environment. c-Fos + cells were counted and analyzed using Cell Voyager CV1000 software. Shown is a comparison of the number of cFos + cells between Std and Enr environment. We used a one-way ANOVA to compare these two conditions, with brain regions showing statistically significant differences as follows $(n=3,3)$ : $\mathrm{m} 1\left(F_{(1,49)}=44.42, p<0.001\right)$; $\operatorname{nac}\left(F_{(1,40)}=10.06, p=0.003\right) ;$ lec $\left(F_{(1,39)}=59.50, p<0.001\right)$; $\operatorname{prh}\left(F_{(1,72)}=47.58\right.$, $p<0.001) ; \mathrm{dg}\left(F_{(1,103)}=10.91, p=0.005\right) ; \mathrm{CA} 1\left(F_{(1,80)}=15.36, p<0.001\right) ; C A 3\left(F_{(1,71)}=4.81, p=0.032\right)$; and mec $\left(F_{(1,34)}=11.84, p=0.002\right) . B$, Top, $C a^{2+}$ imaging experimental timeline with a diagram of lens positioning and horizontal section of DG upper blade with GCaMP6f + cells. Bottom left, Representative image of GCAMP6f-expressing cells in the DGC layer (GCL) and lens implantation site. Bottom right, Diagram of experimental environments. Scale bars, $50 \mu \mathrm{m}$. C, Shown on the left are sample images of active DGCs; on the right are the $C \mathrm{a}^{2+}$ events of freely moving animals in Std and Enr conditions (colored letters correspond to circled cells). Scale bar, $50 \mu \mathrm{m}$. D, Scatter plot of the distribution of individual neuronal C ${ }^{2+}{ }^{2}$ event rates in the Std and Enr conditions. Dots represent individual cell event rates. Red indicates line of equivalence. Inset, Distribution of $\mathrm{Ca}^{2+}$ event rates in Std and Enr (Enr) environments (Kolmogorov-Smirnov test, $p<0.001$ ). $\boldsymbol{E}$, Portions of cells exhibiting decreased, elevated, or the same event rate in the Enr condition versus Std condition (likelihood ratio test on multinomial distribution, $p<0.001 ; n=5$ ). Dots represent trial averages. $\boldsymbol{F}$, Averaged changes in event frequency for the groups described in $\boldsymbol{E}$ (decreased: $-0.012 \pm 0.001 \mathrm{~Hz}$, elevated: $0.020 \pm 0.001 \mathrm{~Hz}$ ). Dots represent trial averages. $\mathbf{G}$, Distributions of the AUC for recorded $\mathrm{Ca}^{2+}$ transients in the Enr and Std conditions (Kolmogorov-Smirnov test, $\left.p<0.001\right)$. $\boldsymbol{H}$, Number of cells with detected Ca ${ }^{2+}$ events during the 5 min exposure to each environment (Std: $47.9 \pm 2.0$ cells, Enr: $50.5 \pm 2.1$ cells, 2-tailed paired t test $p=0.052$ ). Dots represent trial averages. Primary motor cortex (m1), nucleus accumbens (nac), lateral septum (sep), lateral entorhinal cortex (lec), perirhinal cortex (prh), substantia nigra pars reticulata (snr), DG, CA1, CA3, primary auditory cortex (a1), substantia nigra pars compacta (snc), hypothalamus (hypo), amygdala (amyg), medial entorhinal cortex (mec), and raphe nucleus (raph). HC, Home cage. Statistical significance was defined as ${ }^{*} p<0.05,{ }^{* *} p<0.01$. 
shown in Figure $1 F$, suggesting that the animals' locomotion was likely not a key factor inducing the increase at least in this set of tests (Fig. $2 A-C$ ).

Having observed elevated firing of sparsely active DGCs in a novel Enr environment, we next sought to decipher the potential source of this enhanced activation. We hypothesized that the enhanced DGC firing would be associated with object exploration in an Enr environment because the DG is critical for object recognition and pattern separation (Leutgeb et al., 2007; Jessberger et al., 2009). We exposed mice to Enr environments consisting of four distinct objects, the locations of which we henceforth refer to as "object zones," whereas the rest of the arena we designated as "open zones" (Fig. 3A). The corresponding locations were detected in a Std environment lacking objects (object zones and open zones, respectively). As expected, we found that DGC activity was significantly elevated when animals were located in object zones of the Enr environment compared with object zones of the Std environment (Fig. 3B, KolmogorovSmirnov test, $p<0.001, n=217$ cells from 4 animals). Surprisingly, the DGCs were also more active in open zones of the Enr environment than in open zones of the Std environment, although the difference was smaller in magnitude (Fig. 3C, Kolmogoro$\mathrm{v}-$ Smirnov test, $p<0.001)$. Interestingly, when we dissected DGC activity within the Enr environment, we observed a significantly elevated event rate when animals were located in object zones compared with open zones (Fig. 3D, Kolmogorov-Smirnov test, $p<0.001)$. Comparing the number of cells exhibiting an elevated versus a depressed versus an equal firing rate between object and open zones, we observed a significant elevation in the number of cells that elevated their firing rate and more total cells firing when animals were located in object zones (Fig. 3E, F, likelihood ratio test on multinomial distribution $p=0.042 ; 2$-tailed paired $t$ test, $p=0.007$, respectively).

In sum, our results show that, during brief exposure to a novel Enr environment, enhanced hippocampal neural circuit activation was reflected in a preferential increase in the firing of sparsely active DGCs, with a slight increase in the number of active DGCs. The heightened firing of active DGCs in an Enr environment was principally induced by object exploration.

\section{Rapid habituation of enhanced DGC activity in an unchanged Enr environment}

We next investigated whether the enrichment-induced elevation of DGC activity would be retained over time. As outlined in Figure $4 A$,

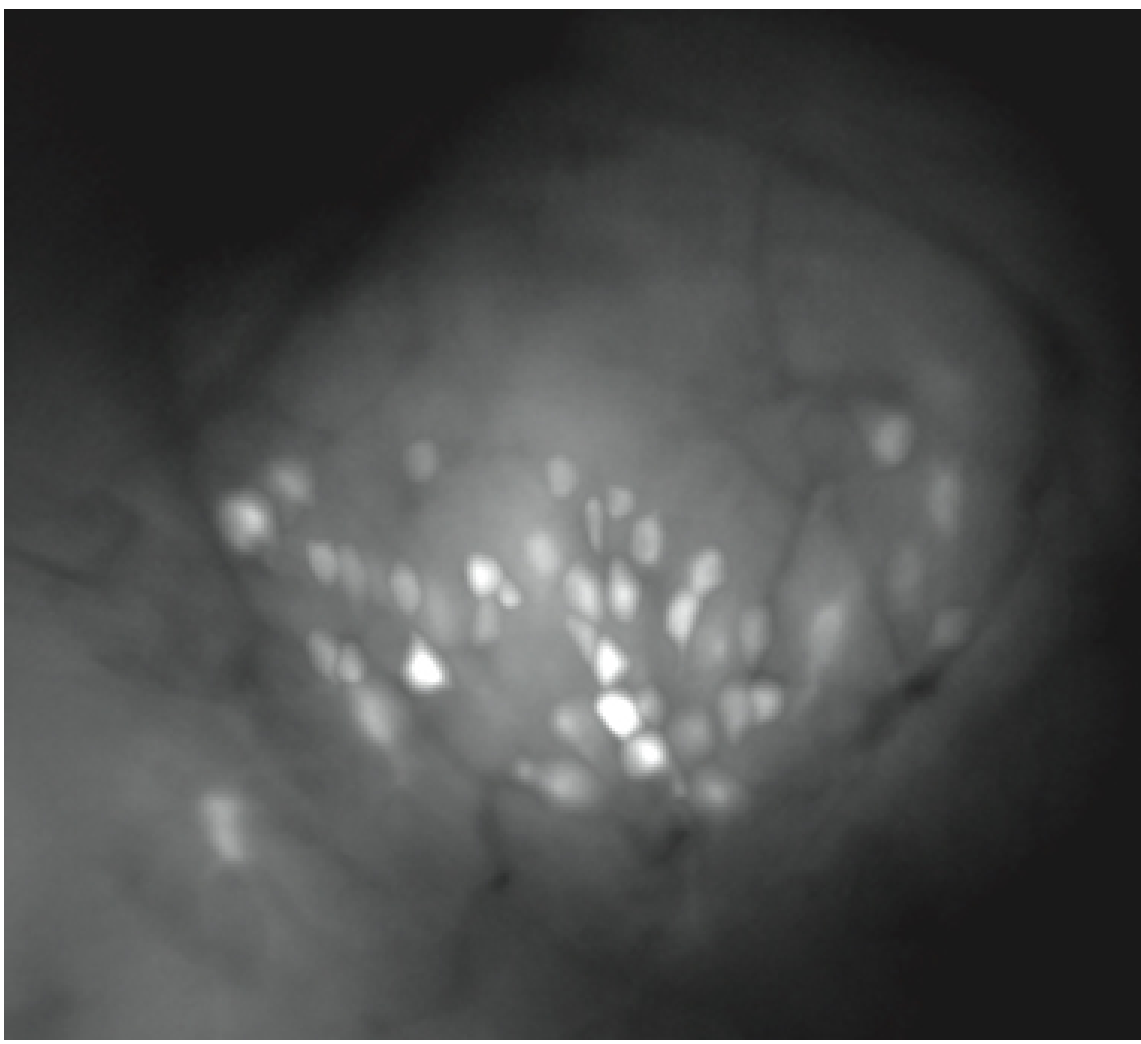

Movie 1. Calcium imaging of the GCL from $0-5$ min in a Std environment (in real time).

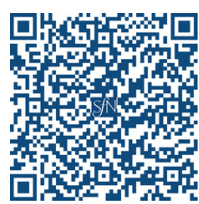

A

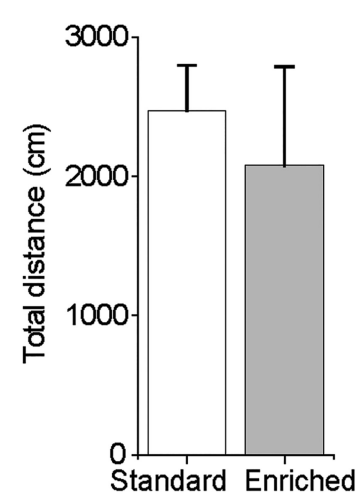

B

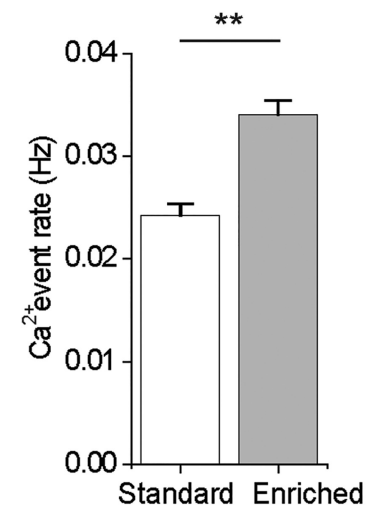

C

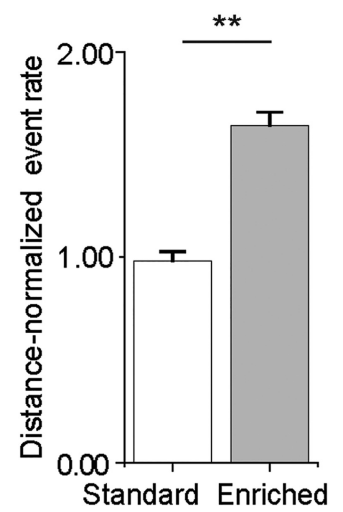

Figure 2. Enrichment-induced $\mathrm{Ca}^{2+}$ transient frequency increase among active DGCs was independent of traveling distance. $\boldsymbol{A}$, Total distance traveled during the 5 min exposure periods for Enr and Std environment-exposed mice (Std: $2472.8 \pm 323.5 \mathrm{~cm}$; Enr: $2077.8 \pm 710.6 \mathrm{~cm}$; 2-tailed unpaired $t$ test $p=0.631) . \boldsymbol{B}$, Global average $\mathrm{Ca}^{2+}$ event rate for cells recorded in the Enr environment compared with the Std environment (Std: $0.024 \pm 0.001 \mathrm{~Hz}$, Enr: $0.034 \pm 0.001 \mathrm{~Hz}$, 2-tailed paired ttest $p<0.001$ ). C, Distance-normalized global average $\mathrm{Ca}^{2+}$ event rate in the Enr environment compared with the Std environment (Std: $9.81^{*} 10^{-6} \pm$ $0.46^{*} 10^{-6}$, Enr: $1.64 \times 10^{-6} \pm 0.65^{*} 10^{-6}, 2$-tailed paired $t$ test $\left.p<0.001\right)$. Data are normalized by dividing event rate values by the number of centimeters traveled per each trial. Statistical significance was defined as ${ }^{*} p<0.05,{ }^{* *} p<0.01$.

we established a 5 min baseline recording in a Std environment and then transferred animals to an Enr environment and recorded periodically over the ensuing hour. The exposure order was fixed and a different cohort of animals was used for this set of experiments compared with that of Figure 1. We found that the majority of cells 
A

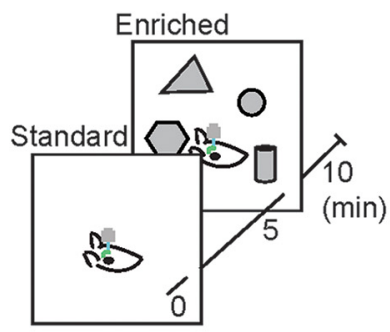

B

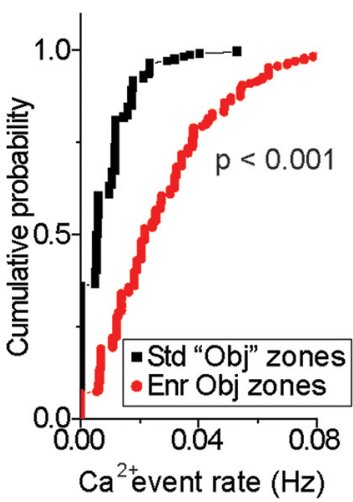

D

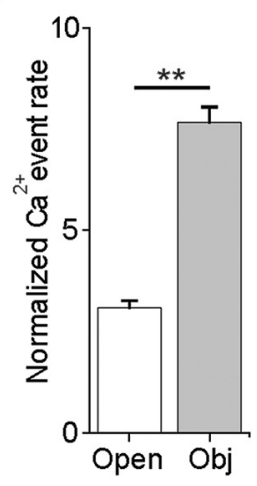

E
C

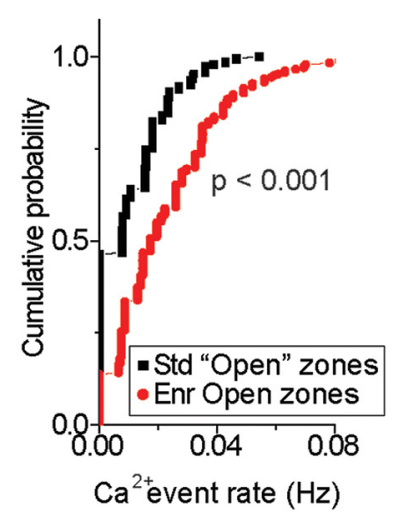

$\mathbf{F}$
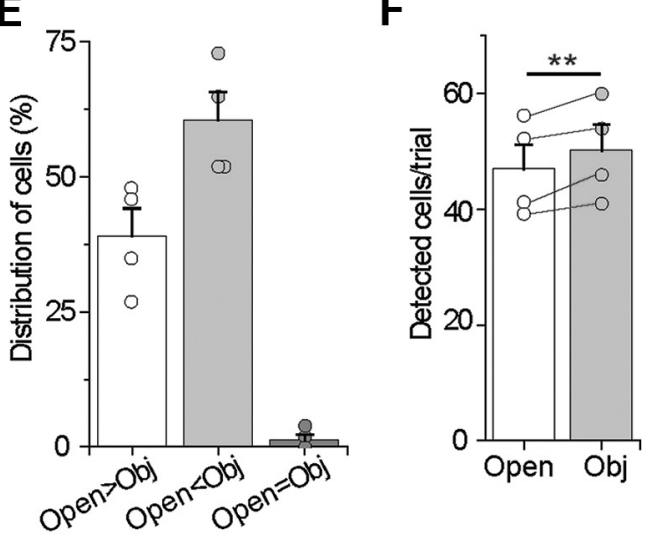

the later time points) (Fig $4 H-J$ ). In contrast, the total number of active cells exhibited a slight, though not statistically significant, initial increase, similar to our finding in Figure $1 H$ (Fig. $4 K$ ).

Together, this set of data indicates that exploration in a novel Enr environment increased the activity of a majority of active DGCs over just the initial exposure period, which is $\sim 25 \mathrm{~min}$, as monitored by their $\mathrm{Ca}^{2+}$ transients. This short-term elevation was sufficient to affect the local circuit because we were able to see more c-Fos expression at $135 \mathrm{~min}$ after a brief, 20 min enrichment exposure (Fig. 5A,B).

Figure 3. Enhanced DGC firing was associated with object exploration. $A$, Diagram of the behavioral paradigm, with 4 objects placed in object zones and the remainder of the field designated as open zones. Object zones were defined as a $2.0 \mathrm{~cm}$ radius surrounding each object. $\boldsymbol{B}$, Distribution of $\mathrm{Ca}^{2+}$ event rates in Std and Enr (Enr) environments in areas corresponding to object zones (Kolmogorov-Smirnov test, $p<0.001 ; n=217$ cells from 4 animals). $C$, Distribution of $\mathrm{Ca}^{2+}$ event rates in Std and Enr environments in areas corresponding to open zones (Kolmogorov-Smirnov test, $p<0.001$ ). D. Plot of $\mathrm{Ca}^{2+}$ event rates in the Enr condition comparing epochs in which mice were located in object zones and open zones (Kolmogorov-Smirnov test, $p<0.001$ ). Data are normalized to the areas encompassed by the object zones and open zones, respectively (units are in $\mathrm{Hz} / \mathrm{cm}^{*} 10^{-5}$ ). $\boldsymbol{E}$, Portions of cells exhibiting decreased, elevated, or the same event rate in the object zones versus open zones (likelihood ratio test on multinomial distribution $p=0.042$ ). Dots represent trial averages. $F$, Number of detected cells per trial in object and open zones (open zones: $47.0 \pm 4.1$ cells, object zones: $50.3 \pm 4.2$ cells; 2-tailed paired $t$ test $p=0.007$ ). Dots represent trial averages. Statistical significance was defined as ${ }^{*} p<0.05,{ }^{* *} p<0.01$.

consistently exhibited an elevated event rate in the Enr environment, as measured by $\mathrm{Ca}^{2+}$ transients during the first 5 min compared with the baseline recording (Fig. $4 B, C, n=130$ cells from 3 animals), consistent with our findings in Figure 1. Interestingly, this elevated firing rate returned to baseline by $1 \mathrm{~h}$ in the same environment (Fig. 4D,E).

To further characterize the kinetics of this rise and fall in firing in an Enr environment, we analyzed intermediate time points at 10-15 and 20-25 min after initial exposure. Consistent with the findings above, the distribution curve showing relative $\mathrm{Ca}^{2+}$ influx of recorded DGCs shifted downward from the initial $5 \mathrm{~min}$ in the Enr environment to the last $5 \mathrm{~min}$ in the same environment (Fig. $4 F$ ). Importantly, the average fluorescence signal of the field of view exhibited no significant photobleaching across the imaging period in the Enr environment, ruling out the possibility that the decay in signal resulted from photobleaching (Bonnot et al., 2014) (Fig. 4G). The average event rate of all recorded DGCs dampened by 10 and $20 \mathrm{~min}$ and returned to basal levels by $1 \mathrm{~h}$, with a similar trend in elevation and decay noted when $\mathrm{Ca}^{2+}$ event rates were normalized by total distance traveled during each imaging period (which remained comparable throughout $p=0.0015$, Trial 1 vs Trial 3: $p=0.108$; Trial 2 vs Trial 3: $p=$ $0.07 ; n=234$ cells from 4 animals). This increase in activity was associated with a trend toward more cells elevating their firing rate versus depressing their firing rate in the novel Enr environment, whereas the total number of cells recruited between environments remained comparable, consistent with our findings in Figure $1 E$ and $H$, respectively (Fig. $6 C, D$, likelihood ratio test on multinomial distribution $p=0.092$; 2 -tailed paired $t$ test $p=$ 0.933 , respectively). Because we found that the firing of active DGCs habituated and then dishabituated from Trial $1 \rightarrow$ Trial 2 $\rightarrow$ Trial 3, we wondered whether we would observe a similar behavioral habituation and dishabituation in object exploration across these three trials. Although we observed a small decrease in object exploration in Trial 2 versus Trial 1, we mainly observed a trend toward increased exploration in Trial 3 compared with the other two trials, although this was not significant (Fig. 6E, oneway ANOVA: $\left.F_{(2,9)}=2.50, p=0.137\right)$.

To further elucidate what this novel-environment-associated firing increase could represent, we next coupled the animals' trajectories with their time-synced $\mathrm{Ca}^{2+}$ event data for each re- 

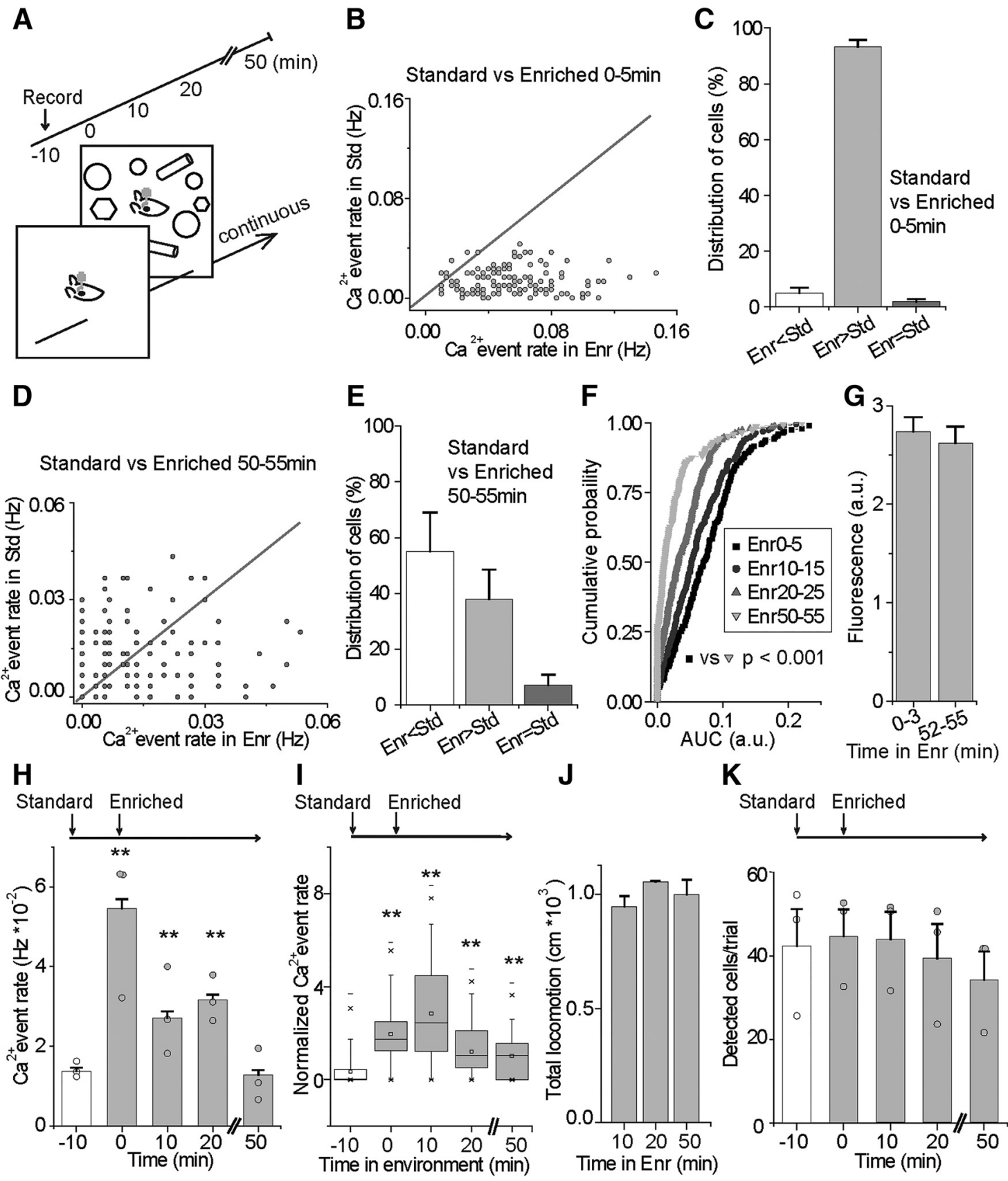

Standard
vs Enriched

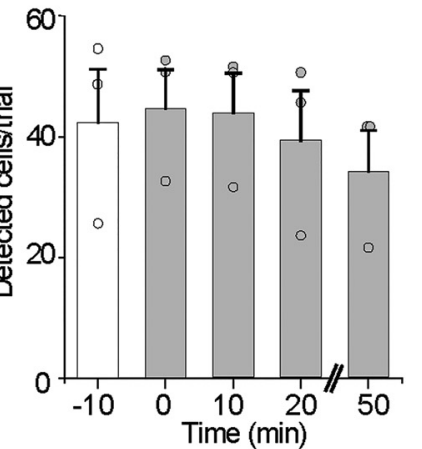

Figure 4. Enr environment-induced DGC activation habituated by $1 \mathrm{~h}$ in the same environment. $A$, Experimental timeline. Five-minute recordings were taken at -10 min in the $S t d$ environment and at 0 , 10,20 , and $50 \mathrm{~min}$ in the Enr environment. $\boldsymbol{B}$, Scatter plot of the distribution of $\mathrm{Ca}^{2+}$ event rates of cells in the Std and the first 5 min of the Enr environment. Dots represent individual cell event rates. Gray line indicates line of equivalence. $C$, Portions of cells exhibiting decreased, elevated, or the same event rate in the Enr versus Std condition (likelihood ratio test on multinomial distribution, $p<0.001 ; n=130$ cells from 3 animals). $\boldsymbol{D}$, Scatter plot of the distribution of $\mathrm{Ca}^{2+}$ event rates of cells in the Std environment and $50-55 \mathrm{~min}$ in the Enr environment. Dots represent individual cell event rates. Gray line indicates line of equivalence. $\boldsymbol{E}$, Portions of cells exhibiting decreased, elevated or the same event rate in the Enr ( $50-55 \mathrm{~min})$ versus $S$ td condition (likelihood ratio test on multinomial distribution $p=0.324) . \boldsymbol{F}$, AUC distributions for cells at 0, 10, 20, and 50 min in the same Enr environment. ( $0-5$ v $50-55$ min: Kolmogorov-Smirnov test $p<0.001)$. G, Average fluorescence signal in the lens' field of view from $0-3$ min and $52-55$ min in the same Enr environment (0-3 min: $2.74 \pm 0.15,2.62 \pm 0.17$ fluorescence units; 2 -tailed unpaired $t$ test $p=0.626)$. $\boldsymbol{H}$, Averaged $\mathrm{Ca}^{2+}$ event rate of all active DGCs in the Enr compared with the Std environment at -10 to $-5,0-5,10-20,20-25$, and $50-55$ min in the Enr environment (one-way ANOVA $F_{(4,640)}=119.1, p<0.001$, followed by Dunnett 2-tailed $t$ tests: Std vs Enr $0-5$ min: $p<0.001$; Std vs Enr $10-15 \min p<0.001$; Std vs Enr $20-25 \min p<0.001$; Std vs Enr $50-55$ min: $p=0.986)$. Dots represent trial averages. I, Distance-normalized global averaged Ca ${ }^{2+}$ event rates in Std and Enr environments at recorded time points (one-way ANOVA $F_{(4,640)}=119.1, p<0.001$, followed by Dunnett's 2-tailed $t$ tests: Std vs Enr $0-5$ min: $p<0.001$; Std vs Enr 10-15 min $p<0.001 ;$ Std vs Enr 20-25 $\min p<0.001$; Std vs Enr $50-55$ min: $p<0.001$ ). Data are normalized by dividing event rate values by number of centimeters traveled per each trial.J, Total locomotion of animals in the Enr environment over time (10 - 15 min: $998.5 \pm 46.2 \mathrm{~cm}, 20-25 \mathrm{~min}: 1085.5 \pm 4.8 \mathrm{~cm}, 886.85 \pm 225.9 \mathrm{~cm}$ ). $\boldsymbol{K}$, Number of cells with detected events in the Std and Enr environments at recorded time points (one-way ANOVA $\left.F_{(4,10)}=0.326, p=0.855\right)$. Dots represent trial averages. Statistical significance was defined as ${ }^{*} p<0.05$, ${ }^{* *} p<0.01$.

corded neuron across the three trials. Intriguingly, not only did we identify location-specific firing among the active DGCs when animals were reexposed to the same environment, but we also observed that this DGC ensemble underwent firing location re- mapping in the novel environment (Fig. $6 F$ ). Indeed, individual neurons' firing fields shifted to a significantly greater extent when the animal was exposed to the novel compared with the familiar environment (Fig. 6G, 2-tailed paired $t$ test $p=0.0029$ ). 
A
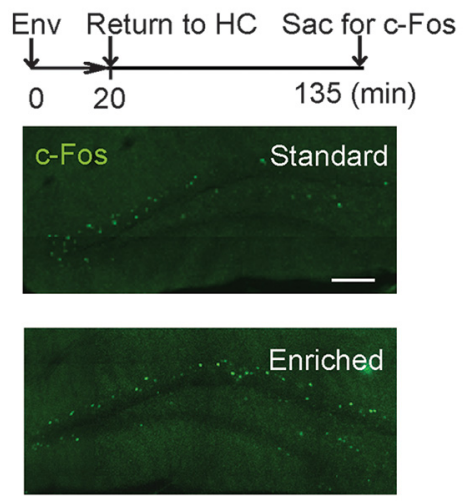

B

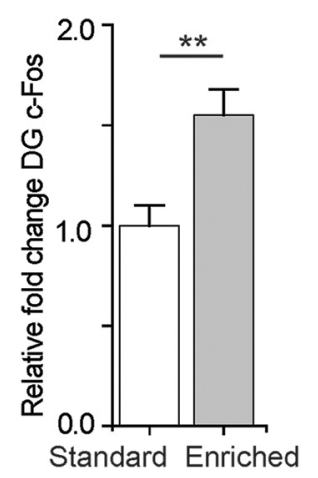

Figure 5. Brief, 20 min exposure to an Enr environment was sufficient to elevate c-Fos expression in the DG. $A$, Experimental procedure is shown above. Shown below are representative images of c-Fos staining in the DG of mice exposed to 20 min of a Std or Enr environment. $\boldsymbol{B}$, Plot of c-Fos + cells in the DG after a 20 min exposure to an Enr or Std environment (relative fold change in c-Fos + cells: Std: $1.00 \pm 0.10$, Enr: $1.55 \pm 0.13$, 2-tailed unpaired $t$ test $p=$ $0.002 ; n=3,3)$. Env, Environment; HC, home cage. Scale bar, $100 \mu \mathrm{m}$. Statistical significance was defined as ${ }^{*} p<0.05,{ }^{* *} p<0.01$.

Together, this set of findings suggests that explorationinduced DGC activity can be dishabituated after decay by exposure to a similar but novel Enr environment. Moreover, the active DGC ensemble exhibits location specific firing and this placecoding ensemble undergoes remapping in a distinct context. This is consistent with the role of the DG in pattern separation (Leutgeb et al., 2007) and suggests a potential role of active DGCs in spatial learning and memory.

\section{Virtual environmental enrichment promotes the addition of new hippocampal neurons}

The short-term elevated activation of DGCs in an Enr environment that could be dishabituated upon exposure to a novel Enr environment (Figs. 1, 2, 3, 4, 5, 6) led us to wonder whether continuously introducing novel Enr environments would lead to an accumulating increase in the addition of new hippocampal neurons. To transition seamlessly between an array of environments without physically disturbing the behaving animal, we developed a VR system with a library of custom-programmed virtual environments for unrestrained mice to explore via an airlifted spherical treadmill (Fig. 7A).

As a proof of principle, we first confirmed that non-head-fixed mice could indeed interact with and explore within a VR environment. We established a virtual navigation task in which waterdeprived mice were trained to navigate to a virtual target zone for a water reward (Fig. $7 B$ ). One group of mice was trained to navigate to the virtual target zone and a second group was rewarded at random intervals throughout the training period. The two groups received the same amount of water reward. As expected, trained mice navigated to the target zone significantly more than those in the untrained condition and entered the target zone with a significantly shorter latency (Fig. 7C-F). Further, trained mice were significantly more often located in the reward zone corner compared with any other corner of the virtual arena (Fig. 7G). This behavioral test in the novel VR system indicated that rodents are capable of unrestrained virtual navigation, as reported with head-fixed virtual navigation (Hölscher et al., 2005; Dombeck et al., 2010; Chen et al., 2013a; Aronov and Tank, 2014).

We thus tested whether exploration in an virtual Enr environment would affect the addition rate of new hippocampal neu-

rons. To analyze directly the number of newborn neurons, we adapted a method we used previously for labeling cell clusters derived from single dividing progenitors (Song et al., 2012). In brief, we expressed Cre recombinase in GFAP-expressing cells using a lentivirus under the control of a mouse GFAP promoter (Lenti-GFAP-Cre) (Fig. 8A), known to be expressed in radial glia-like cells (Kempermann et al., 2004; Mignone et al., 2004). We developed a retroviral DF-Cre reporting vector, in which a given reverse orientation transgene such as GFP (rGFP) could be flipped and inserted into the flip excision cassette (Fig. 8A) upon the presence of Cre recombinase. By stereotaxic coinfusion of the GFAP-cre and DF-rGFP viruses into the DG, we were able to label active GFAP + cells in the hilus/subgranular zone. In general, we were able to tag 7-15 active, single, radial-glia like cells per animal analyzed $1 \mathrm{~d}$ after viral injection. As we described previously with transgenic mice (Song et al., 2012), we used this method to analyze the generation and integration of new neurons derived from a single GFAP + cell several days after labeling.

To confirm that experience would affect the addition rate of new hippocampal neurons, we assigned mice randomly to either a real Enr or Std environment after a $1 \mathrm{~d}$ recovery from surgery to label GFAP+ progenitor cells. We exposed them to their respective environments for 12 consecutive days (Fig. 8A). As expected, all GFP-expressing cells exhibited features of typical DGCs as we described previously (Ge et al., 2006) (Fig. 8B). Importantly, exposure to the real Enr environment significantly amplified the size of GFP + clusters as shown in Figure $8 B(p=0.024 ; n=4,4$ mice per group), demonstrating an increased generation of adult-born cells at $12 \mathrm{~d}$ after injection.

To determine whether virtual environmental enrichment exposure would affect this neuronal addition, we delivered the labeling viruses (Fig. $8 A$ ) into the hippocampus and then exposed mice to either virtual Std or Enr environments for 12 consecutive days (Fig. $8 C$ ) after a $1 \mathrm{~d}$ recovery from surgery. As shown in Figure $8 D$, there was a substantial increase in the size of GFP+ DGC clusters in mice exposed to the virtual Enr environment (Fig. 8D; 2-tailed unpaired $t$ test $p<0.001, n=5,5$ /group). We then verified this observation using the traditional thymidine analog BrdU pulse-chase approach (Kuhn et al., 1996). Mice received a single intraperitoneal injection of BrdU before being exposed to 12 consecutive days of a virtual Enr or Std environment. There were significantly more BrdU-labeled cells in the DG of mice exposed to the virtual Enr environment (Fig. $8 E$; 2 -tailed unpaired $t$ test $p=0.0142 ; n=10,9$ /group). Importantly, the effect sizes that we observed between the BrdU pulsechase and viral lineage tracing approaches were comparable (1.55- and 1.57-fold increase over Std condition, respectively) and were consistent with previous findings using a similar real enrichment exposure paradigm (Llorens-Martín et al., 2010). Also consistent with previous studies of real environmental enrichment demonstrating minimal effects on progenitor cell proliferation (Kempermann et al., 1997; Olson et al., 2006), we found that virtual environmental enrichment did not significantly alter the number of BrdU+ cells analyzed at $48 \mathrm{~h}$ after injection (Fig. 8F; 2-tailed unpaired $t$ test $p=0.401, n=3,3$ /group). Together, these results suggest, not only that mice were able to navigate freely within a virtual environment, but also that the virtual environmental enrichment is sufficient to promote the addition of new hippocampal neurons.

Multiple virtual Enr environments introduce an accumulative increase in the number of new hippocampal neurons

Because we found that the firing elevation in an Enr environment could be dishabituated by introducing the animal to a novel environment (Fig. 6), we sought to determine the effect of contin- 
A

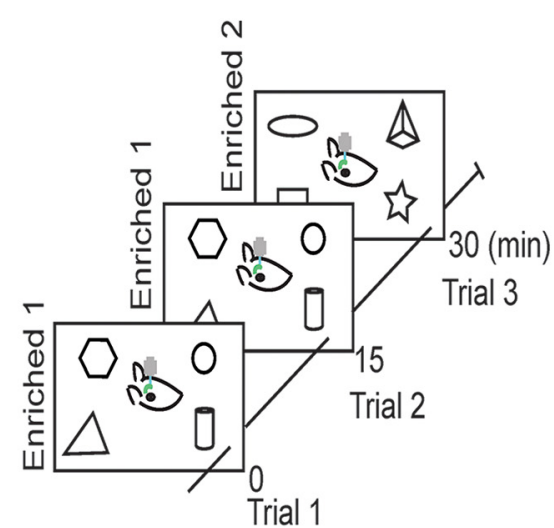

D

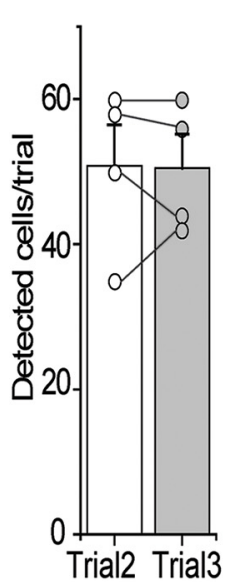

E

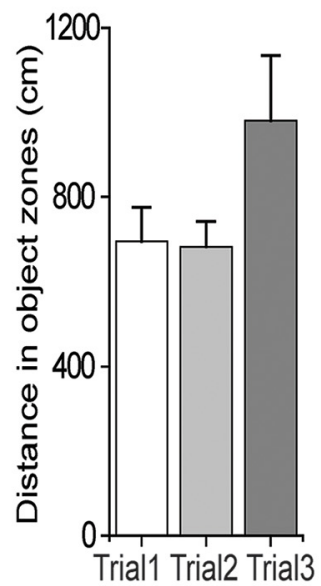

B

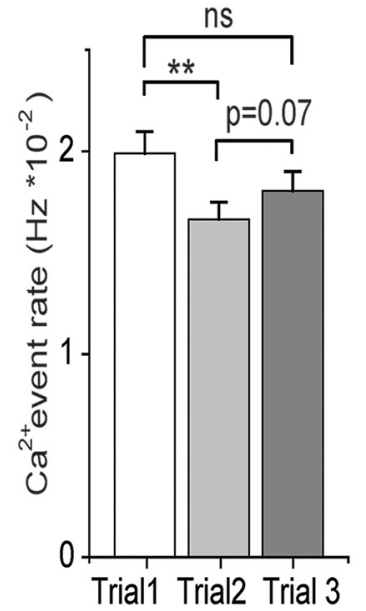

C

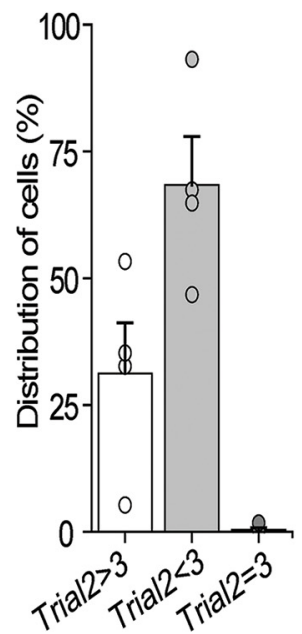

G
F

$$
\text { Trial } 1 \text { Trial } 2
$$

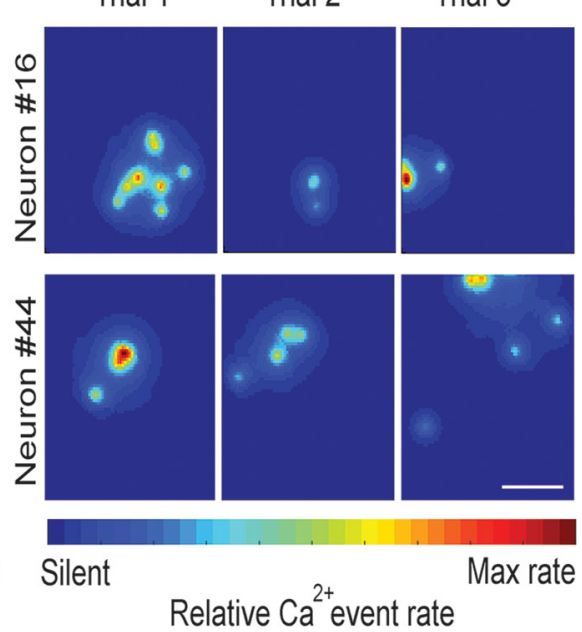

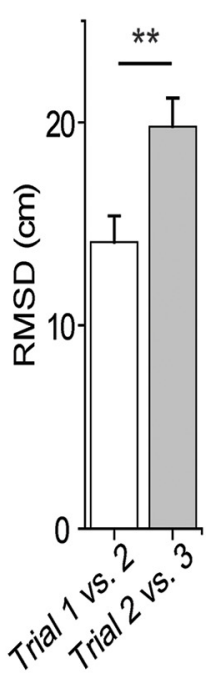

Figure 6. Decay in DGC firing in a familiar Enr environment dishabituated upon introduction to a novel Enr environment. $\boldsymbol{A}$, Experimental timeline. GCaMP6f-injected mice were exposed to a familiar Enr environment (Enr 1) twice and a novel Enr environment (Enr 2) for 5 min recording sessions spaced 10 min apart. $\mathrm{Ca}^{2+}$ transients were recorded for each 5 min exposure period with simultaneous motion tracking. $\boldsymbol{B}$, Plot of $\mathrm{Ca}^{2+}$ event rates during Trials 1, 2, and 3 (one-way ANOVA with repeated measures $F_{(1,216)}=24.18, p<0.001$; followed by post hoc paired $t$ tests: Trial 1 vs Trial 2: $p=0.0015$; Trial 1 vs Trial 3: $p=0.108$; Trial 2 vs Trial 3: $p=0.07$ ). C, Portions of cells exhibiting decreased, elevated, or the same event rate in Trial 2 and Trial 3 (likelihood ratio test on multinomial distribution $p=0.092$ ). Dots represent trial averages. $D$, Number of detected cells per trial in Trial 2 and Trial 3 (Trial 2:50.8 \pm 5.7 cells, Trial $3: 50.5 \pm 4.4$ cells; 2 -tailed paired $t$ test, $p=0.933)$. Dots represent trial averages. $\boldsymbol{E}$, Plot of the distance animals traveled in the object zones across the three trials (Trial 1:694.8 $\pm 80.2 \mathrm{~cm}$, Trial $2: 681.5 \pm 60.0 \mathrm{~cm}$, Trial $3: 980.0 \pm 155.2$ $\mathrm{cm}$; one-way ANOVA $\left.F_{(2,9)}=2.50, p=0.137\right)$. $\boldsymbol{F}$, Representative heat maps of relative $\mathrm{Ca}^{2+}$ event rates in the same spatial location taken from two neurons (Neuron \#16 and \#44) across the three trials. G, Plot of the root mean square deviation between Trial 1 versus Trial 2 and Trial 2 versus Trial 3 (Trial 1 vs Trial 2: $14.1 \pm 1.3 \mathrm{~cm}$, Trial 2 vs Trial $3: 19.8 \pm 1.4 \mathrm{~cm} ; 2$-tailed unpaired $t$ test $p=$ 0.0029). Scale bar, $5 \mathrm{~cm}$. Statistical significance was defined as ${ }^{*} p<0.05,{ }^{* *} p<0.01$.

uously introducing novel Enr environments on the addition of new hippocampal neurons. To this end, we developed 12 virtual Enr environments and assigned mice to receive either "single enrichment," consisting of daily exposure to the same virtual environment across all days, or "multiple enrichment," consisting of daily exposure to two distinct, randomly selected environments from a virtual library, for 12 consecutive days. All mice were given a single intraperitoneal $\mathrm{BrdU}$ injection on the first day, as in Figure 8E (Fig. 9A). We found that exposure to multiple enrichment significantly elevated the number of $\mathrm{BrdU}+$ cells in the DG compared with single enrichment (Fig. 9B, $p=0.007 ; n=$ 6,5 /group). We confirmed this observation using the viral lineage tracing approach as described in Figure 8 following the protocol as outlined in Figure $8 \mathrm{~A}$. We observed a similar expansion in the size of newborn DGC clusters of mice in the multiple enrichment group (Fig. 9C, 2-tailed unpaired $t$ test $p=0.019 ; n=3$ /group). These results indicate that exposure to multiple novel Enr environments promoted the addition of new hippocampal neurons accumulatively.

Virtual Enr environment enhances the firing of active DGCs To determine whether virtual exploration would promote the firing of active DGCs as we observed in real Enr environments (Figs. 1, 2, 3, 4, 5, 6), we exposed GCaMP6f-labeled mice to a Std or a novel virtual Enr environment and recorded $\mathrm{Ca}^{2+}$ transients over a $5 \mathrm{~min}$ period (Fig. 10A), following a similar procedure as we performed for the data shown in Figure 1. As shown in Figure $10 B$ and $C$, the event frequency distribution was significantly elevated in the virtual Enr environment (Fig. 10B,C, KolmogorovSmirnov test $p<0.001 ; n=359$ cells from 4 animals). This was 
A

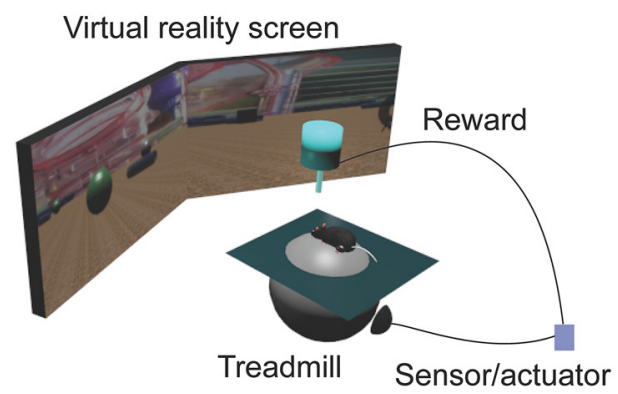

B

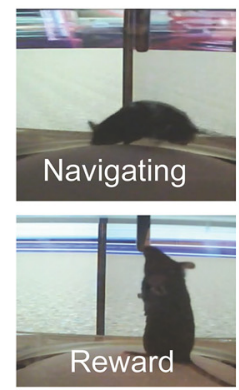

C

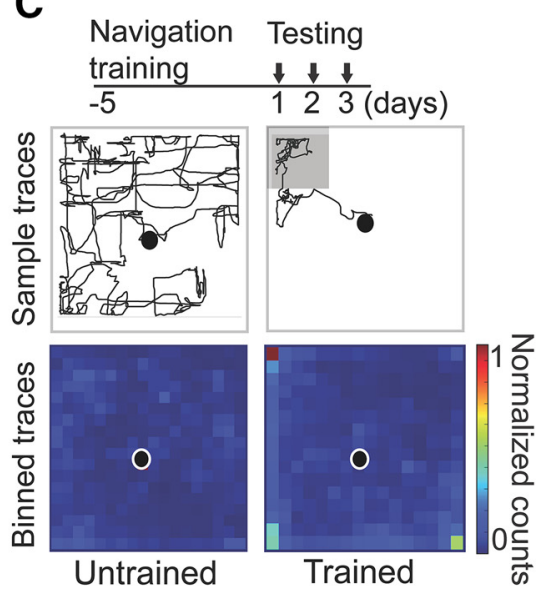

D

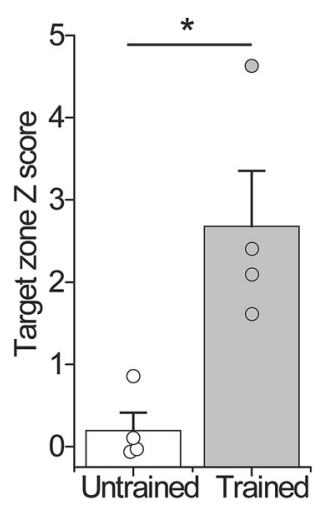

E

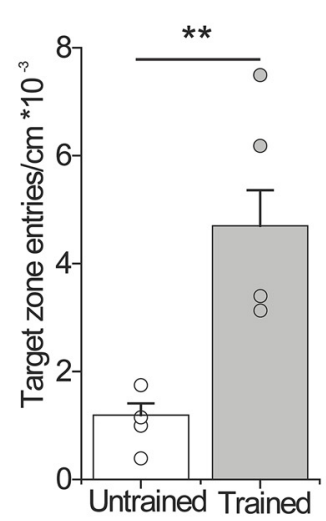

F

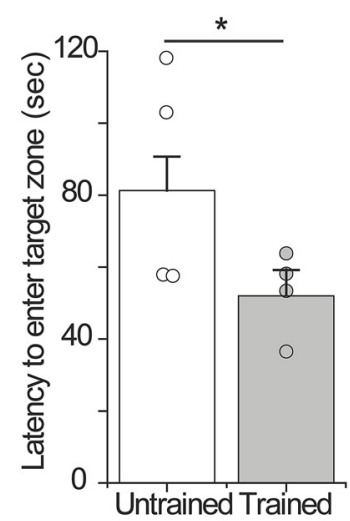

G

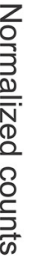

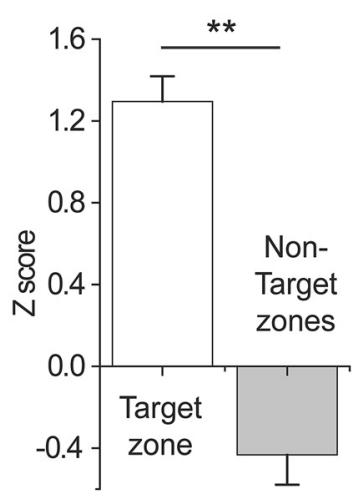

Figure 7. Mice learned to navigate unrestrained in a VR environment. $\boldsymbol{A}$, Controllable VR apparatus for unrestrained mice with motion tracking and automated reward delivery system. $\boldsymbol{B}$, Sample images of mouse navigating to a virtual reward location and receiving a water reward. C, Top, Training and testing paradigm in the virtual arena. Bottom, Sample and cumulative traces of mice in the trained condition and the untrained condition. $D, Z$ score of reward target zone entries for trained and untrained mice ( $Z$ score of target zone bin vs nontarget zone bins $0.193 \pm 0.220$ for

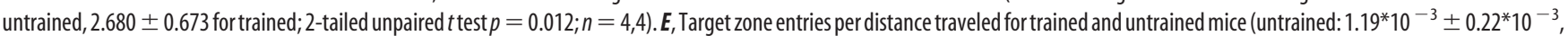
trained: $4.70 \pm 0.66^{*} 10^{-3}$, respectively; 2 -tailed unpaired $t$ test $p<0.001$ ). $\boldsymbol{F}$, Latency to enter the target zone for trained and untrained mice (untrained: $81.27 \pm 9.41 \mathrm{~s}$, trained: $51.98 \pm 7.17 \mathrm{~s}$; 2-tailed unpaired $t$ test $p=0.016, n=4,4)$. G,Z score of target zone corner and nontarget zone corners for trained mice (target zone: 1.295 $\pm 0.124 ;$ nontarget zones $=-0.432 \pm 0.147 ; 2$-tailed unpaired $t$ test $p<0.001 ; n=4)$. Dots represent individual animals. Statistical significance was defined as ${ }^{*} p<0.05,{ }^{* *} p<0.01$.

confirmed by the distribution of cells' relative event rates between the two environments, as shown in Figure 10D. Similar to the analysis in Figure $1 G$, we also observed a significantly elevated shift in the $\mathrm{Ca}^{2+}$ influx distribution in the virtual Enr environment (Fig. 10E, Kolmogorov-Smirnov test, $p<0.001$ ). As expected, when we counted the number of active DGCs under these two conditions, we detected no change (Fig. $10 F, p=0.702$ ). Finally, we verified that a virtual Enr experience would promote $c$-fos expression in the DG by conducting a similar experiment to that described in Figure $1 A$, in this case using a virtual Enr or virtual Std environment as the exposure conditions. Indeed, we observed significantly more c-Fos + cells in the DG of mice exposed to virtual enrichment (Fig. $10 G, p=0.0039, n=3,4$ /group). Interestingly, when we exposed mice to either a familiar virtual Enr environment to which they had been previously exposed or two novel virtual Enr environments to which they had not been previously exposed, we observed a significant increase in c-Fos + cells in mice exposed to the novel Enr environments, consistent with our findings in Figure 6 (Fig. $10 H, p=0.013, n=$ 4,4/group).

Together, these results show that exposure to a virtual Enr environment increased dentate activity by increasing the $\mathrm{Ca}^{2+}$ transient frequency of active DGCs with comparable changes as those induced by a real Enr environment.

\section{Optical silencing of DGCs during novel environmental exploration abolishes experience-induced addition of new hippocampal neurons}

Finally, we set out to test whether DGC activation during novel experiences is essential to exploratory experience-induced addition of new hippocampal neurons. We optogenetically silenced DGCs acutely during enrichment-based exploration and examined the number of new hippocampal neurons. We stereotaxically injected an AAV containing Halo or GFP as a control under the CaMKII promoter into the DG. We then implanted an optrode for subsequent light stimulation and allowed 2 weeks for expression of the Halo and GFP as we described previously (Gu et al., 2012; Song et al., 2012) (Fig. 11A). We administered a single intraperitoneal BrdU injection and then exposed mice to 12 consecutive days in either an Enr or a Std environment for $2 \mathrm{~h}$ per session, during which time both groups of mice received orange light stimulation pulsed at $1 \mathrm{~Hz}$. After the last session, we killed the animals and analyzed BrdU incorporation in the DG. As expected, we found a significant increase in BrdU + cells in the GCL 
A

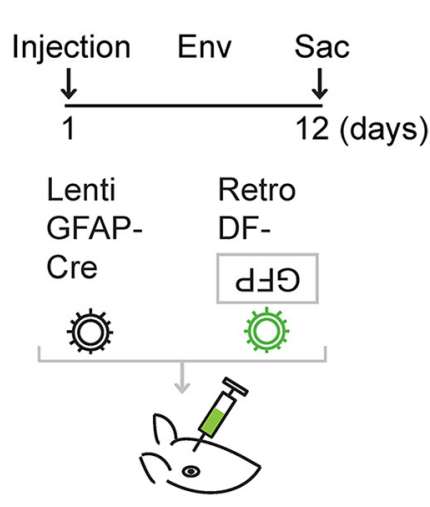

D
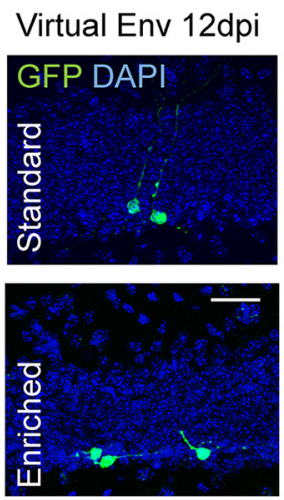

B

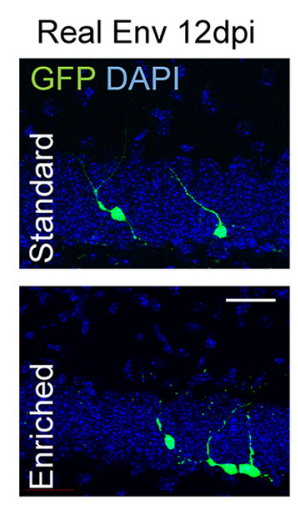

$\mathbf{E}$
C

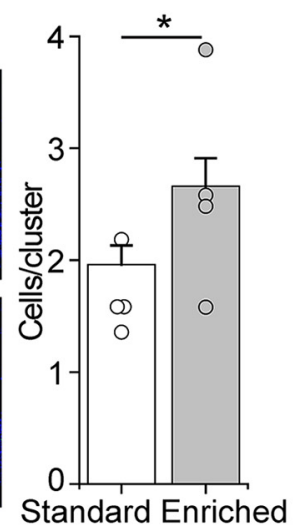

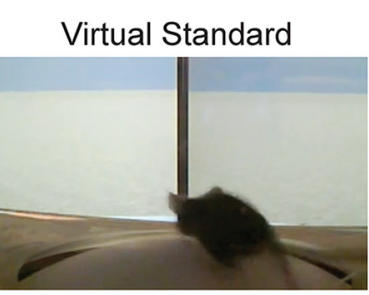

Virtual Enriched

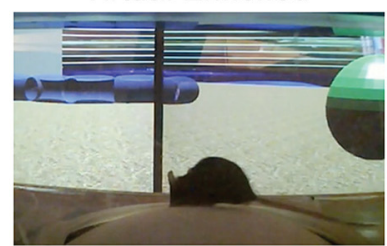

$\mathbf{F}$

BrdU Virtual Sac
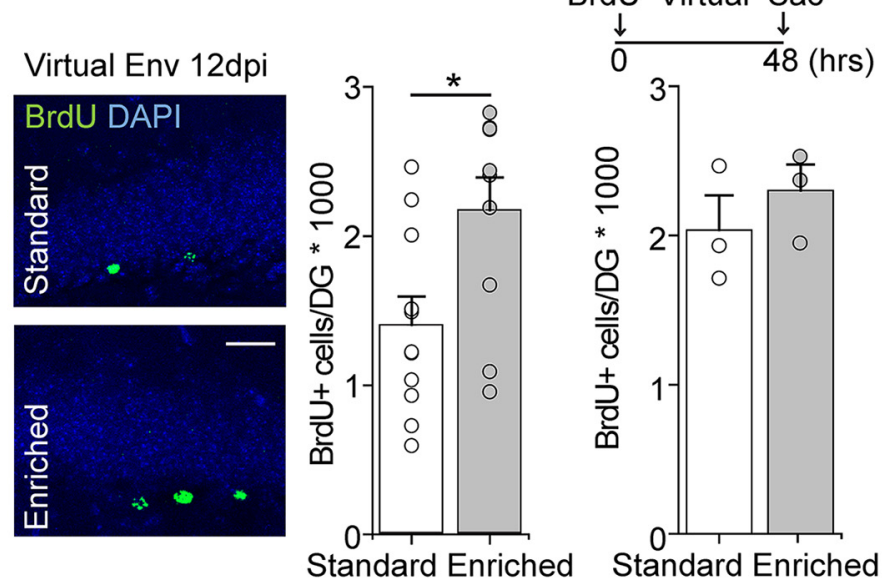

Figure 8. Virtual environmental enrichment increased the addition of adult-born hippocampal neurons. $\boldsymbol{A}$, Experimental timeline (top) and diagram of virally mediated lineage tracing in which lenti-GFAP-Cre and retro-DF-reverse GFP are coinjected into the DG (bottom). $\boldsymbol{B}$, Left, Representative images of 12-d-old DGC clusters in the DGC layer in Std- and Enr environment-exposed mice. Right, Plots of average cell cluster size in these groups (Std: $1.97 \pm 0.17$ cells/cluster, Enr: $2.66 \pm 0.25$ cells/cluster; 2 -tailed unpaired $t$ test $p=0.024 ; n=4,4$ ). Scale bar, $30 \mu m$. C, Sample images of mice exploring in virtual Std (top) and Enr (bottom) environments. $D$, Left, Representative images of 12-d-old cell clusters in the GCL of the DG in virtual Std- and Enr environment-exposed mice. Right, Plots of average cell cluster size for mice exposed to a virtual Enr compared with those exposed to a virtual Std environment (Std: $1.63 \pm 0.12$ cells/cluster; Enr: $2.55 \pm 0.20$ cells/cluster; 2-tailed unpaired $t$ test $p<0.001 ; n=5,5)$. $E$, Left, Representative images of 12-d-old BrdU + cells in the GCL of the DG in Std-and Enr-exposed mice. Right, Plots of average number of BrdU+ cells of mice in the virtual Enr condition compared with those in the virtual Std condition (Std: $1404.7 \pm 190.7$ cells, Enr: $2175.2 \pm 220.1$ BrdU + cells; 2 -tailed unpaired $t$ test: $p=0.0142 ; n=10,9)$. $\boldsymbol{F}$, Experimental timeline (top) and number of BrdU + cells of mice exposed to $48 \mathrm{~h}$ of a virtual Std or Enr environment (bottom) (Std: $2036.3 \pm 223.5$ cells, Enr: $2302 \pm 173.3$ cells; 2 -tailed unpaired $t$ test $p=0.401 ; n=3,3$ ). Dots represent individual animals. Statistical significance was defined as ${ }^{*} p<0.05,{ }^{* *} p<0.01$.

of the GFP group exposed to the Enr environment. In contrast, there was little change in the number of BrdU + cells in Haloexpressing mice exposed to the Enr environment (Fig. 11B, 2-tailed unpaired $t$ tests $p=0.025, p=0.818$, respectively; $n=5$ /group). To confirm the successful manipulation of DGC activation, we performed post hoc analysis of c-Fos expression given the inherent challenge of monitoring DGC activity simultaneously during optogenetic silencing. As expected, we found a substantial increase in c-Fos expression in the GFP Enr condition, whereas there was no significant change in the Halo group (Fig. 11C, 2-tailed unpaired $t$ tests $p<0.001, p=0.370$, respectively). We noted no significant difference between GFP-Enr and Halo-Enr groups in terms of the amount of time spent exploring objects within the environment across the initial $10 \mathrm{~min}$ of exposure (Fig. 11D).

To determine whether the initially elevated firing rate that we observed in Figures 4 and 5 is essential for experience-induced neuronal addition, we performed a similar experiment as outlined in Figure $11 A$, but limited the period of DG silencing to just the first $25 \mathrm{~min}$ of environmental exposure (the period in which we had observed elevated firing of existing DGCs in Figs. 4, 5) (Fig. 11E). After the initial $25 \mathrm{~min}$, the light was turned off and animals were permitted to explore in their respective environments for the remaining $95 \mathrm{~min}$. On the final day of exposure, we killed animals for post hoc c-Fos and BrdU analyses. Importantly, we found that $25 \mathrm{~min}$ of light was sufficient to suppress the c-Fos elevation in the Halo-Enr mice (Fig. 11E; 2-tailed unpaired $t$ test $p=0.695)$. We likewise observed no change in BrdU+ cells between groups (Fig. 11E; 2-tailed unpaired $t$ test, $p=0.854$ ).

These findings suggest that suppressing the initial activation of DGCs during novel environmental experiences disrupted experience-based addition of new hippocampal neurons, implicating active DGCs as playing an essential role in regulating the addition of new hippocampal neurons.

\section{Discussion}

To determine mechanistically how the existing brain circuitry encodes a novel experience to affect hippocampal plasticity, we studied the circuit activity of the dorsal DG during exploratory 
A

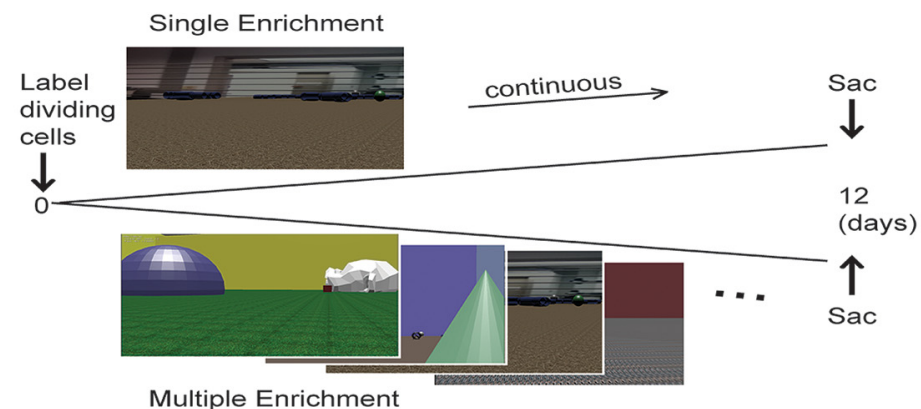

B
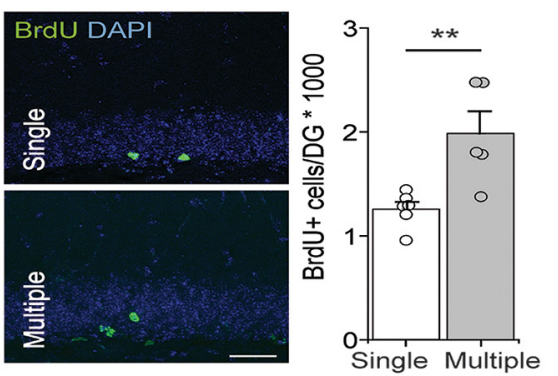

C
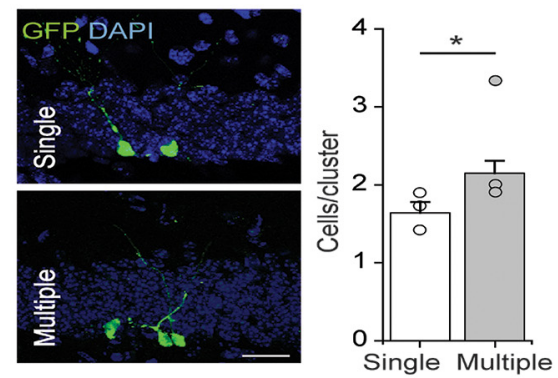

Figure 9. Multiple virtual Enr environments cumulatively promoted hippocampal neuronal addition. $\boldsymbol{A}$, Experimental timeline. Mice were exposed to either a single Enr environment or multiple Enr environments (2/d) during each exposure session. $\boldsymbol{B}$, Left, Representative images of $\mathrm{BrdU}+$ cells in the $\mathrm{GCL}$ of single- and multiple enrichment-exposed mice. Scale bar, $30 \mu \mathrm{m}$. Right, Plots of the number of BrdU+ cells in the $\mathrm{GCL}$ of mice exposed to the multiple enrichment and single enrichment groups (single enrichment: $1256.7 \pm 68.5$ cells, multiple enrichment: $1982.4 \pm 214.7$ cells, 2-tailed unpaired $t$ test $p=0.007 ; n=6,5)$. C, Left, Representative images of GFP + cell clusters in the GCL of single- and multiple enrichment-exposed mice. Scale bar, $30 \mu \mathrm{m}$. Right, Plots of the average cell cluster size for mice exposed to multiple enrichment compared with those exposed to single enrichment (single enrichment: $1.64 \pm 0.14$ cells/cluster; multiple enrichment: $2.15 \pm 0.16$ cells/cluster; 2 -tailed unpaired $t$ test $p=0.019$; $n=3$,3). Scale bars, $30 \mu \mathrm{m}$. Dots represent individual animals. Statistical significance was defined as ${ }^{*} p<0.05,{ }^{* *} p<0.01$.
(Kempermann et al., 1997; Brown et al., 2003; Rossi et al., 2006). In the present study, we used exposure to Enr environments to study how the trisynaptic circuit encodes exploration-related activity to influence the addition of new hippocampal neurons. To transition seamlessly between complex environments, we developed a freely controllable VR system with customprogrammed environments that could be called noninvasively and randomly from a coded environment library. As shown in Figures 7, 8, 9, and 10, we found that animals could perform a spatial navigation task unrestrained in the virtual arena and that virtual exploration induced analogous changes in dentate firing activity and neurogenesis as its real-world counterpart.

One advantage of the VR system that we established compared with more traditional Enr environments is the lack of spatial constraints. For example, most studies of environmental enrichment conducted to date have used relatively small, Enr cages with a limited number of objects and other spatial cues that may serve to activate the DG circuit and trigger increased neuronal addition (Kempermann et al., 1997, 1998; Brown et al., 2003). Indeed, one study that used an Enr environment with the same spatial constraints as the Std control environment failed to identify an effect of environmental comexperiences, which are known to promote the survival of new hippocampal neurons (van Praag et al., 2000; Kirschen et al., 2016). To observe DG activity directly in awake, behaving animals on a large spatial scale, we established an in vivo $\mathrm{Ca}^{2+}$ imaging method and found that the dorsal DG, which is critically important in spatial information processing (Moser and Moser, 1998; Hampson et al., 1999), responds to a novel experience by increasing the firing rate of its active neurons preferentially. Surprisingly, this effect was short lived, decaying back to baseline levels within $1 \mathrm{~h}$ of the exposure to the same environment. More importantly, the decay in elevated firing could be dishabituated by introducing animals to a distinct Enr environment. Using a novel unrestrained VR paradigm, we found that multiple Enr experiences further increased the number of new hippocampal neurons to be added into the existing circuit. Ongoing activity within the trisynaptic circuit during this environmental exploration is likely critical for novel experience-induced hippocampal neuron addition because silencing the existing DG network muted this enhancement.

Novel environmental exploration activates various brain circuits and increases synaptic plasticity, particularly in the trisynaptic circuit, which processes spatial information for memory encoding and retrieval (Abraham et al., 2002; Leutgeb et al., 2005; Kee et al., 2007; Li et al., 2013). In this circuit, integration of new hippocampal neurons has been widely acknowledged to provide an additional layer of structural and functional plasticity (Jessberger and Gage, 2008, 2014; Sahay et al., 2011b; Cameron and Glover, 2015). Enr environments, which promote exploration and enhance hippocampal neurogenesis dramatically, have been used widely to study how behavior translates into neuroplasticity plexity on experience-induced neurogenesis (Grégoire et al., 2014). Conversely, real, naturalistic environments are enriched by many orders of magnitude compared with those used in the laboratory setting. Here, we designed richly complex virtual environments containing dozens of objects and varying in size up to $16 \mathrm{~m}^{2}$. Despite the lack of other sensory cues present in realworld environments (e.g., olfactory, somatosensory), the complex spatial landscape of our virtual environments was sufficient, not only to activate the mature DG circuit, but also to trigger experience-dependent neuronal addition.

An important question that future investigations should address pertains to the behavioral consequences of hippocampal neuronal addition induced by multiple novel experiences. Previous work has established that environmental enrichment improves spatial memory performance in rodents (Kempermann et al., 1997; Nilsson et al., 1999; Williams et al., 2001) and that the number of new neurons influences this behavioral facilitation (Sahay et al., 2011a; McAvoy et al., 2016). Adult-born neurons in the DG have been shown to be critical for encoding contextual information and for relaying this information to CA3 target projections for subsequent recall, especially in cases of highly overlapping representations (Jessberger et al., 2009; Sahay et al., 2011a; Denny et al., 2014). It will be interesting to determine whether new neurons resulting from multiple novel experiences confer any particular advantages to learning or memory of contextual or spatial information.

Because DGCs are the principal local excitatory cells in the DG, we focused on the circuit in which these cells participate. More importantly, many of the regions that we identified with a significantly elevated c-Fos expression profile in the Enr environ- 
A

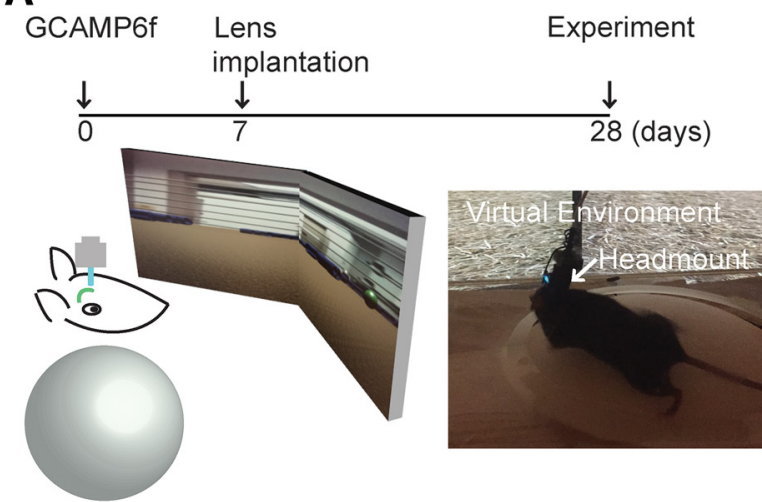

C

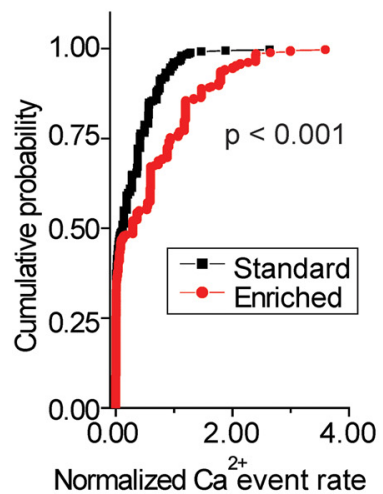

G

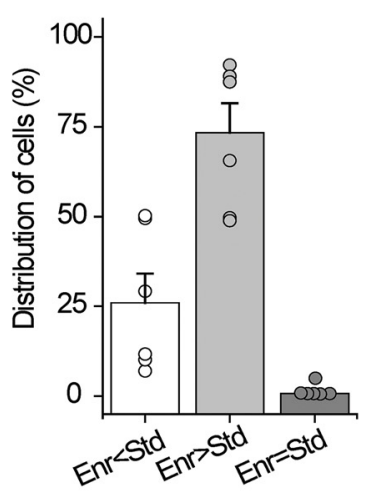

H
B

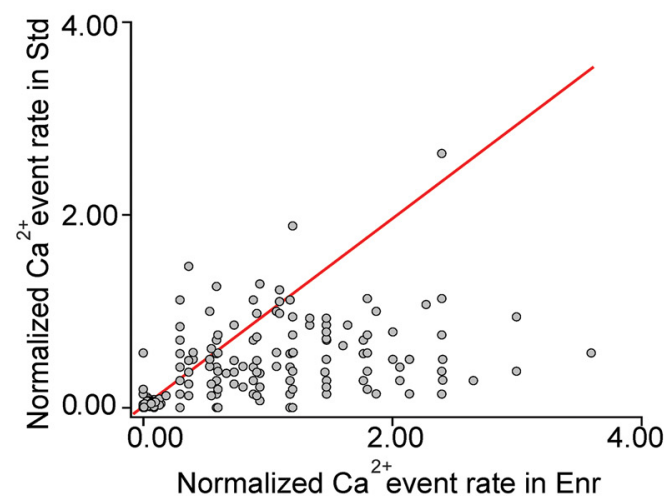

E

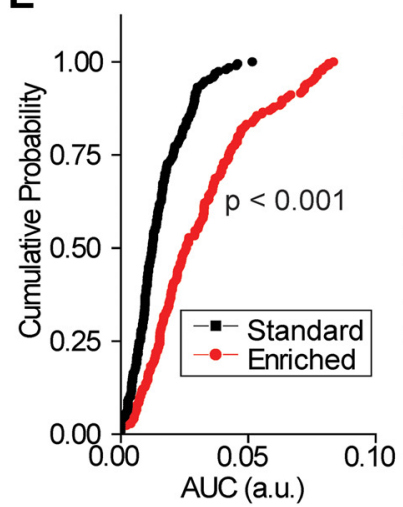

$F$

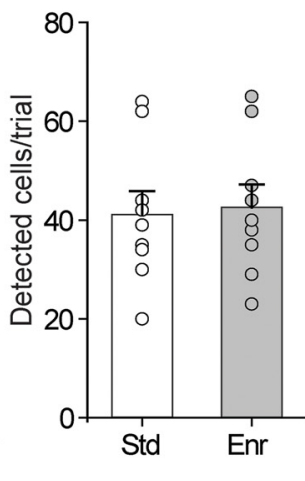

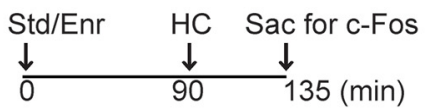
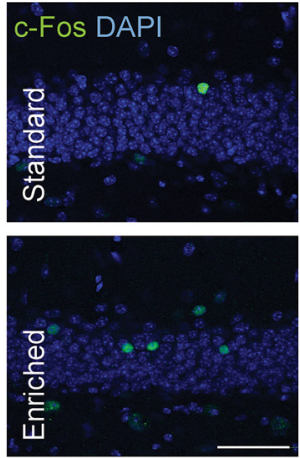
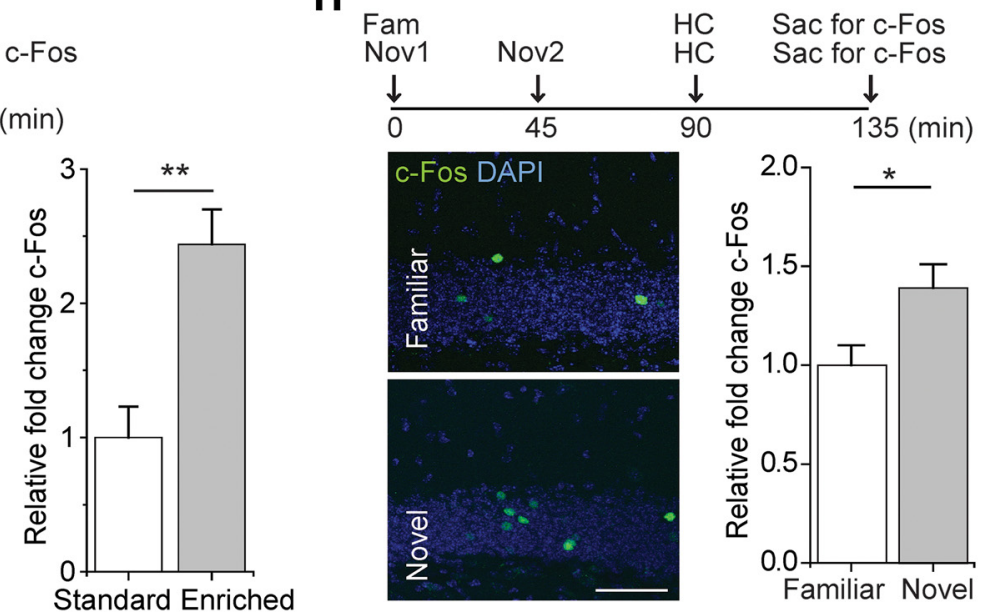

Figure 10. Virtual Enr environments promote the firing of active DGCS. A, Experimental timeline (top) and diagram (bottom left) and representative image (bottom right) of a mouse freely exploring in a virtual environment with simultaneous $\mathrm{Ca}^{2+}$ transient monitoring. $\boldsymbol{B}$, Scatter plot of the distribution of $\mathrm{Ca}^{2+}$ event rates of cells in the virtual Std environment and virtual Enr environment. Dots represent individual cell event rates. Red represents line of equivalence. Data are normalized by dividing event rate values by distance traveled (in units of $\mathrm{Hz} / \mathrm{cm}^{*} 10^{-4}$ ). $C$, Distribution of $\mathrm{Ca}^{2+}$ event rates in the Enr compared with the Std condition (Kolmogorov-Smirnov test, $p<0.001 ; n=359$ cells from 4 animals). Data are normalized by dividing event rate values by distance traveled (in units of $\mathrm{Hz} / \mathrm{cm}^{*} 10^{-4}$ ). $D$, Portions of cells exhibiting decreased, elevated, or the same event rate in the Enr condition versus Std condition (likelihood ratio test on multinomial distribution $p<0.001$ ). Dots represent trial averages. E, Distributions of the AUC for recorded $\mathrm{Ca}^{2+}$ transients in the Enr and Std conditions (Kolmogorov-Smirnovtest, $p<0.001$ ). $\boldsymbol{F}$, Number of cells detected pertrial in the virtual Enr and Std conditions (Std:41.1 \pm 4.8 cells, Enr: $42.6 \pm 4.6$ cells; 2 -tailed paired $t$ test $p=0.702$ ). Dots represent trial averages. G, Left, Exposure timeline and representative images of c-Fos- stained cells in the GCL of the DG in virtual Std and Enr environment-exposed mice. Scale bar, $30 \mu \mathrm{m}$. Right, Plot of c-Fos + cells in the GCL of mice exposed to virtual Std or Enr environments (relativefold change: Std: 1.00 \pm 0.23 ; Enr: 2.44 \pm 0.26 ; 2-tailed unpaired $t$ test $p=0.0039 ; n=3,4) . \boldsymbol{H}$, Left, Representative images of c-fos + cells in the GCL of the DG of single, familiar Enr environment (Fam)- and multiple, novel Enr environment (Nov)-exposed mice. Scale bar, $30 \mu \mathrm{m}$. Right, Plot of c-Fos + cells in the GCL of mice in the multiple enrichment condition compared with those in the single enrichment condition (relative fold change in c-Fos + cells: Fam: $1.00 \pm 0.13$, Nov: $1.39 \pm 0.12 ; 2$-tailed unpaired $t$ test $p=0.013 ; n=4,4)$. Statistical significance was defined as ${ }^{*} p<0.05,{ }^{* *} p<0.01$.

ment outside of the hippocampus project directly to the DG (Fig. $1 A)$. Of course, whether this other circuit activity contributes to neurogenesis and activity coding by DGCs remains to be tested. Conversely, the effect of immature DGCs on the activity of the mature circuit during exploratory behavior remains an open question. For example, immature DG neurons are excited preferentially by parvalbumin + interneurons and recruit feedback inhibition onto the mature circuit, facilitating the young neu- 


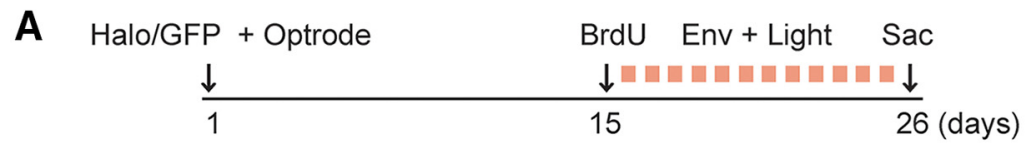

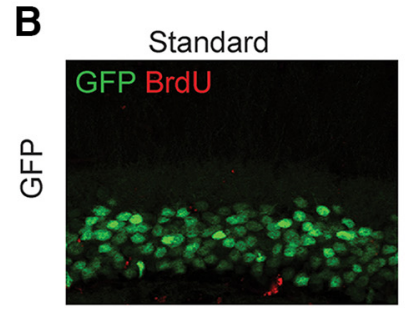

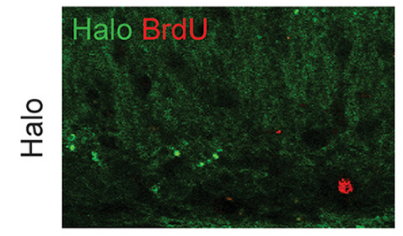

C
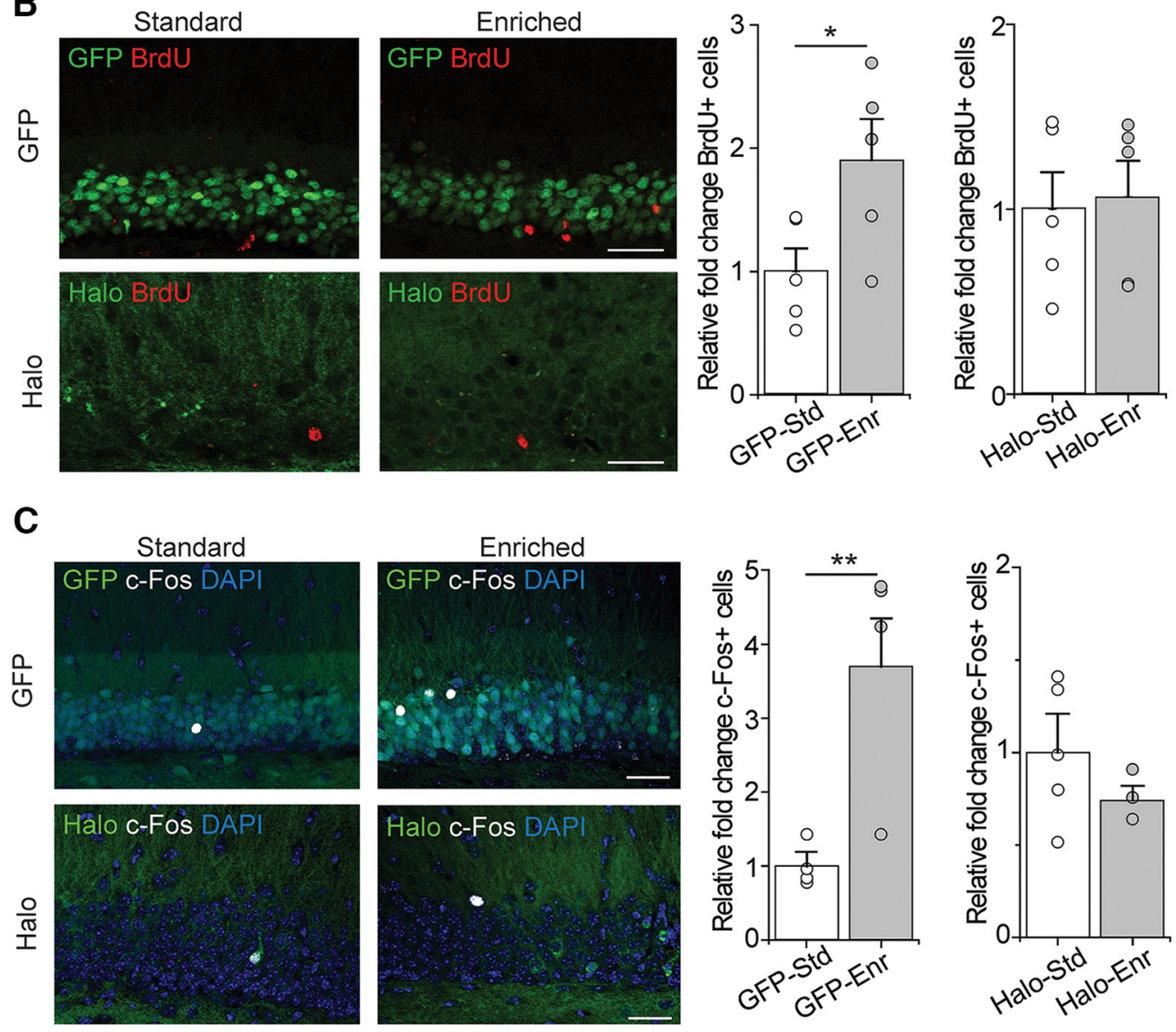

D

E

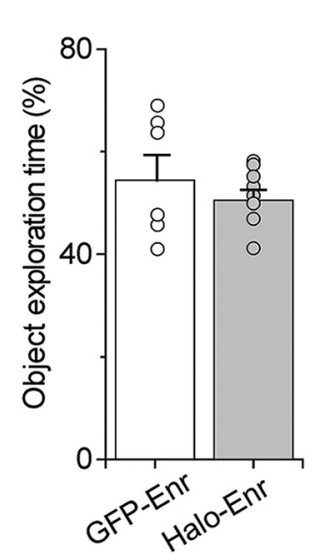

Halo + Optrode

Env +25 min light
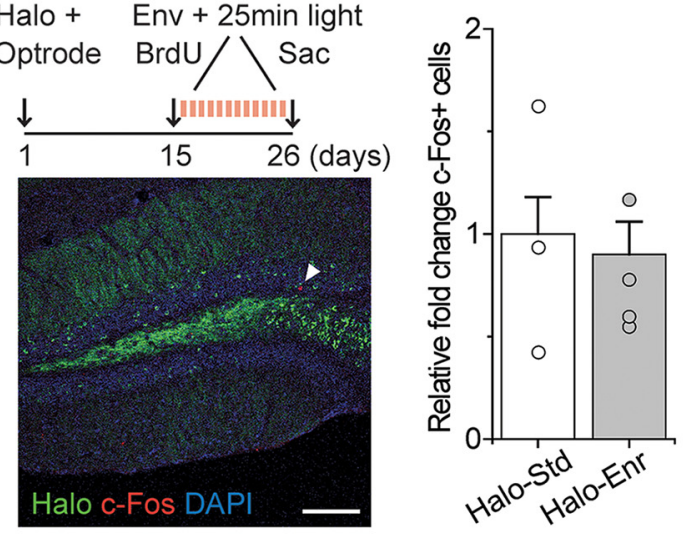

Figure 11. Optical silencing of DGCs abolished enrichment-induced hippocampal neurogenesis. A, Experimental timeline. Mice were injected with AAV-CaMKII-GFP or AAV-CaMKII-Halo and implanted with head mounts for optical stimulation, given 2 weeks to recover, and then given a single intraperitoneal BrdU injection and exposed to either an Enr or Std environment for $12 \mathrm{~d}$ ( $2 \mathrm{~h} / \mathrm{d}$ ) with light stimulation ( $1 \mathrm{~Hz}, 5 \mathrm{~ms}$ in duration). $\boldsymbol{B}$, Left, Representative images of the GCL of the DG from mice in the GFP and Halo groups under Std and Enr environments, respectively. Scale bar, 30 $\mu \mathrm{m}$. Right, Plots of BrdU + cells in the GCL of mice in the GFP-Enr group compared with those in the GFP-Std group (relative fold change in Brdu: GFP-Std: 1.00 \pm 0.17 , GFP-Enr: 1.90 $\pm 0.32,2$-tailed unpaired $t$ test $p=0.025$ ), and BrdU + cells in the GCL of mice in the Halo-Enr compared with those in the Halo-Std group (Halo-Std: 1.00 \pm 0.20 , Halo-Enr: 1.07 \pm 0.20 , 2-tailed unpaired $t$ test $p=0.818$ ). C, Left, Representative images of c-fos staining in the GCL of the DG of AAV-CaMKII-GFP and AAV-CaMKII-Halo injected mice exposed to an Enr or Std environment. Right, Plots of c-Fos + cells in the GCL of mice in the GFP-Enr condition and GFP-Std condition (relative fold change c-Fos + cells/field: GFP-Std: $1.00 \pm 0.19$, GFP-Enr: $3.70 \pm 0.46 ; 2$-tailed unpaired $t$ test $p<0.001$ ). Left, Plots of c-Fos + cells in the GCL of mice in the Halo-Enr condition and Halo-Std condition (Halo-Std: $4.36 \pm 0.59$ c-Fos + cells/field, Halo-Enr:3.57 $\pm 0.64,2$-tailed unpaired $t$ test $p=0.370$ ). D, Plot of the percentage of time that mice spent exploring objects in an Enr environment (GFP-Enr: $54.4 \pm 4.9 \%$, GFP-Halo: $50.5 \pm 2.0 \%$; 2-tailed unpaired $t$ test $p=0.428 ; n=2$ trials each from 3,4 animals). $\boldsymbol{E}$, Top left, Experimental timeline. Bottom left, Representative image of c-Fos staining of the DG taken from a Halo-Enr animal exposed to 25 min of light in an Enr environment. The arrowhead points to a c-Fos + cell. Right, Plots of relative fold change in c-Fos + cells (Halo-Std: $1.00 \pm 0.18$, Halo-Enr: $0.90 \pm 0.16 ; 2$-tailed unpaired $t$ test $p=0.695 ; n=3,4$ ), and BrdU + cells (Halo-Std: $1.00 \pm 0.28$, Halo-Enr: $1.08 \pm 0.26 ; 2$-tailed unpaired $t$ test $p=0.854 ; n=3,4$ ). Dots represent individual animals. Statistical significance was defined as ${ }^{*} p<0.05{ }^{* *} p<0.01$. 
rons' experience-dependent integration (Temprana et al., 2015; Alvarez et al., 2016). Because the DG regulates its overall activity by balancing the firing of mature and immature neurons (Drew et al., 2016; van Ooyen and Butz-Ostendorf, 2017), it will be interesting to see what effect ablating newborn neurons may have on the activity of the existing circuit during novel environmental exploration. Nevertheless, the present study revealed the robust activation of mature DGCs upon an initial exposure to an Enr environment versus a Std one. Surprisingly, we found that an almost entirely overlapping population of active DGCs is recruited in Std, familiar Enr, and novel Enr environments. Given the sparse coding nature of the DG (Chawla et al., 2005; Aimone et al., 2011; Danielson et al., 2016; Pilz et al., 2016), whether other brain areas use similar mechanisms of information coding remains to be determined.

Whether there exist distinct subpopulations of DGCs responsible for coding different aspects of the environmental patterns also remains unknown. Likewise, we found that DGCs exhibited place field-like features in their firing pattern (O'Keefe and Burgess, 1996), but the place-coding properties of the DG require further investigation.

We found that DGCs appear to act in a rapid and circuitautonomous fashion to promote enrichment-induced addition of new hippocampal neurons because specific silencing of preexisting DGCs during even just the initial phase of environmental exploration was sufficient to abolish this enhancement (Fig. 11E). Interestingly, silencing the DG circuit did not seem to disrupt exploratory behavior during initial contextual exposure (Fig. $11 D)$. We hypothesize that this may be due to the fact that, here, we silenced the mature circuit but because neurogenesis was intact, simple contextual tasks such as free object exploration (versus, for example, goal-directed navigation or cued contextual recall) may be the job of new adult-born neurons compared with mature ones (Saxe et al., 2007; Drew et al., 2010; Gu et al., 2012). Alternatively, the mature DG circuit may not participate directly in the generation of exploratory behavior during initial context exposure per se, but rather may act simply as an encoder of contextual information (which may be necessary to trigger an increase in neurogenesis).

Along with in vivo imaging of activity in other hippocampal subregions during active spatial information gathering and processing (Dombeck et al., 2010), these findings pose exciting new questions regarding the online coordination of activity in the trisynaptic circuit in the intact brain, especially because new neurons are in the process of actively integrating. Importantly, we found that this activity is likely essential to encode information necessary to promote the rate of addition of new hippocampal neurons.

In sum, we have shown that preexisting active DGCs respond to novel experiences by increasing their firing rate to influence the number of newborn neurons to be added into the existing circuit during a certain period. This work advances our understanding of how the adult brain controls its plasticity through regulating the capacity of adult hippocampal neurogenesis. It will be interesting to further investigate the mechanisms by which elevated DG activity is transduced to increase the addition of new neurons in the adult brain.

\section{References}

Abraham WC, Logan B, Greenwood JM, Dragunow M (2002) Induction and experience-dependent consolidation of stable long-term potentiation lasting months in the hippocampus. J Neurosci 22:9626-9634. Medline
Aimone JB, Deng W, Gage FH (2011) Resolving new memories: a critical look at the dentate gyrus, adult neurogenesis, and pattern separation. Neuron 70:589-596. CrossRef Medline

Altman J, Das GD (1965) Autoradiographic and histological evidence of postnatal hippocampal neurogenesis in rats. J Comp Neurol 124:319335. CrossRef Medline

Alvarez DD, Giacomini D, Yang SM, Trinchero MF, Temprana SG, Büttner KA, Beltramone N, Schinder AF (2016) A disynaptic feedback network activated by experience promotes the integration of new granule cells. Science 354:459-465. CrossRef Medline

Aronov D, Tank DW (2014) Engagement of neural circuits underlying 2D spatial navigation in a rodent virtual reality system. Neuron 84:442-456. CrossRef Medline

Ben Abdallah NM, Slomianka L, Vyssotski AL, Lipp HP (2010) Early agerelated changes in adult hippocampal neurogenesis in C57 mice. Neurobiol Aging 31:151-161. CrossRef Medline

Bergami M, Masserdotti G, Temprana SG, Motori E, Eriksson TM, Göbel J, Yang SM, Conzelmann KK, Schinder AF, Götz M, Berninger B (2015) A critical period for experience-dependent remodeling of adult-born neuron connectivity. Neuron 85:710-717. CrossRef Medline

Bonnot A, Guiot E, Hepp R, Cavellini L, Tricoire L, Lambolez B (2014) Single-fluorophore biosensors based on conformation-sensitive GFP variants. FASEB J 28:1375-1385. CrossRef Medline

Brown J, Cooper-Kuhn CM, Kempermann G, Van Praag H, Winkler J, Gage FH, Kuhn HG (2003) Enriched environment and physical activity stimulate hippocampal but not olfactory bulb neurogenesis. Eur J Neurosci 17:2042-2046. CrossRef Medline

Cameron HA, Glover LR (2015) Adult neurogenesis: beyond learning and memory. Annu Rev Psychol 66:53-81. CrossRef Medline

Cameron HA, McKay RD (2001) Adult neurogenesis produces a large pool of new granule cells in the dentate gyrus. J Comp Neurol 435:406-417. CrossRef Medline

Chawla MK, Guzowski JF, Ramirez-Amaya V, Lipa P, Hoffman KL, Marriott LK, Worley PF, McNaughton BL, Barnes CA (2005) Sparse, environmentally selective expression of Arc RNA in the upper blade of the rodent fascia dentata by brief spatial experience. Hippocampus 15:579-586. CrossRef Medline

Chen G, King JA, Burgess N, O’Keefe J (2013a) How vision and movement combine in the hippocampal place code. Proc Natl Acad Sci U S A 110: 378-383. CrossRef Medline

Chen TW, Wardill TJ, Sun Y, Pulver SR, Renninger SL, Baohan A, Schreiter ER, Kerr RA, Orger MB, Jayaraman V, Looger LL, Svoboda K, Kim DS (2013b) Ultrasensitive fluorescent proteins for imaging neuronal activity. Nature 499:295-300. CrossRef Medline

Danielson NB, Kaifosh P, Zaremba JD, Lovett-Barron M, Tsai J, Denny CA, Balough EM, Goldberg AR, Drew LJ, Hen R, Losonczy A, Kheirbek MA (2016) Distinct contribution of adult-born hippocampal granule cells to context encoding. Neuron 90:101-112. CrossRef Medline

Denny CA, Kheirbek MA, Alba EL, Tanaka KF, Brachman RA, Laughman KB, Tomm NK, Turi GF, Losonczy A, Hen R (2014) Hippocampal memory traces are differentially modulated by experience, time, and adult neurogenesis. Neuron 83:189-201. CrossRef Medline

Dombeck DA, Harvey CD, Tian L, Looger LL, Tank DW (2010) Functional imaging of hippocampal place cells at cellular resolution during virtual navigation. Nat Neurosci 13:1433-1440. CrossRef Medline

Drew LJ, Kheirbek MA, Luna VM, Denny CA, Cloidt MA, Wu MV, Jain S, Scharfman HE, Hen R (2016) Activation of local inhibitory circuits in the dentate gyrus by adult-born neurons. Hippocampus 26:763-778. CrossRef Medline

Drew MR, Denny CA, Hen R (2010) Arrest of adult hippocampal neurogenesis in mice impairs single- but not multiple-trial contextual fear conditioning. Behav Neurosci 124:446-454. CrossRef Medline

Freund J, Brandmaier AM, Lewejohann L, Kirste I, Kritzler M, Krüger A, Sachser N, Lindenberger U, Kempermann G (2015) Association between exploratory activity and social individuality in genetically identical mice living in the same enriched environment. Neuroscience 309:140 152. CrossRef Medline

Ge S, Goh EL, Sailor KA, Kitabatake Y, Ming GL, Song H (2006) GABA regulates synaptic integration of newly generated neurons in the adult brain. Nature 439:589-593. CrossRef Medline

Ghosh KK, Burns LD, Cocker ED, Nimmerjahn A, Ziv Y, Gamal AE, 
Schnitzer MJ (2011) Miniaturized integration of a fluorescence microscope. Nat Methods 8:871-878. CrossRef Medline

Gould E, Tanapat P, Hastings NB, Shors TJ (1999) Neurogenesis in adulthood: a possible role in learning. Trends Cogn Sci 3:186-192. CrossRef Medline

Grégoire CA, Bonenfant D, Le Nguyen A, Aumont A, Fernandes KJ (2014) Untangling the influences of voluntary running, environmental complexity, social housing and stress on adult hippocampal neurogenesis. PLoS One 9:e86237. CrossRef Medline

Gu Y, Arruda-Carvalho M, Wang J, Janoschka SR, Josselyn SA, Frankland PW, Ge S (2012) Optical controlling reveals time-dependent roles for adult-born dentate granule cells. Nat Neurosci 15:1700-1706. CrossRef Medline

Gu Y, Janoschka S, Ge S (2013) Neurogenesis and hippocampal plasticity in adult brain. Curr Top Behav Neurosci 15:31-48. CrossRef Medline

Guzowski JF, McNaughton BL, Barnes CA, Worley PF (1999) Environmentspecific expression of the immediate-early gene Arc in hippocampal neuronal ensembles. Nat Neurosci 2:1120-1124. CrossRef Medline

Hampson RE, Simeral JD, Deadwyler SA (1999) Distribution of spatial and nonspatial information in dorsal hippocampus. Nature 402:610-614. CrossRef Medline

Hölscher C, Schnee A, Dahmen H, Setia L, Mallot HA (2005) Rats are able to navigate in virtual environments. J Exp Biol 208:561-569. CrossRef Medline

Hosseiny S, Pietri M, Petit-Paitel A, Zarif H, Heurteaux C, Chabry J, Guyon A (2015) Differential neuronal plasticity in mouse hippocampus associated with various periods of enriched environment during postnatal development. Brain Struct Funct 220:3435-3448. CrossRef Medline

Hsieh J, Schneider JW (2013) Neuroscience. Neural stem cells, excited. Science 339:1534-1535. CrossRef Medline

Jakubs K, Nanobashvili A, Bonde S, Ekdahl CT, Kokaia Z, Kokaia M, Lindvall O (2006) Environment matters: synaptic properties of neurons born in the epileptic adult brain develop to reduce excitability. Neuron 52:10471059. CrossRef Medline

Jessberger S, Gage FH (2008) Stem-cell-associated structural and functional plasticity in the aging hippocampus. Psychol Aging 23:684-691. CrossRef Medline

Jessberger S, Gage FH (2014) Adult neurogenesis: bridging the gap between mice and humans. Trends Cell Biol 24:558-563. CrossRef Medline

Jessberger S, Clark RE, Broadbent NJ, Clemenson GD Jr, Consiglio A, Lie DC, Squire LR, Gage FH (2009) Dentate gyrus-specific knockdown of adult neurogenesis impairs spatial and object recognition memory in adult rats. Learn Mem 16:147-154. CrossRef Medline

Kee N, Teixeira CM, Wang AH, Frankland PW (2007) Preferential incorporation of adult-generated granule cells into spatial memory networks in the dentate gyrus. Nat Neurosci 10:355-362. CrossRef Medline

Kempermann G, Kuhn HG, Gage FH (1997) More hippocampal neurons in adult mice living in an enriched environment. Nature 386:493-495. CrossRef Medline

Kempermann G, Kuhn HG, Gage FH (1998) Experience-induced neurogenesis in the senescent dentate gyrus. J Neurosci 18:3206-3212. Medline

Kempermann G, Jessberger S, Steiner B, Kronenberg G (2004) Milestones of neuronal development in the adult hippocampus. Trends Neurosci 27:447-452. CrossRef Medline

Kirshen GW, Di Antonio A, Ge S (2016) Physiology and plasticity. In: Adult neurogenesis in the hippocampus: health, psychopathology, and brain disease, Ed 1 (Canales J, ed), p 19-40. San Diego: Academic.

Kleim JA, Lussnig E, Schwarz ER, Comery TA, Greenough WT (1996) Synaptogenesis and Fos expression in the motor cortex of the adult rat after motor skill learning. J Neurosci 16:4529-4535. Medline

Kuhn HG, Dickinson-Anson H, Gage FH (1996) Neurogenesis in the dentate gyrus of the adult rat: age-related decrease of neuronal progenitor proliferation. J Neurosci 16:2027-2033. Medline

Lagace DC, Fischer SJ, Eisch AJ (2007) Gender and endogenous levels of estradiol do not influence adult hippocampal neurogenesis in mice. Hippocampus 17:175-180. CrossRef Medline

Leutgeb JK, Leutgeb S, Treves A, Meyer R, Barnes CA, McNaughton BL, Moser MB, Moser EI (2005) Progressive transformation of hippocampal neuronal representations in "morphed" environments. Neuron 48: 345-358. CrossRef Medline

Leutgeb JK, Leutgeb S, Moser MB, Moser EI (2007) Pattern separation in the dentate gyrus and CA3 of the hippocampus. Science 315:961-966. CrossRef Medline

Li S, Jin M, Zhang D, Yang T, Koeglsperger T, Fu H, Selkoe DJ (2013) Environmental novelty activates beta2-adrenergic signaling to prevent the impairment of hippocampal LTP by Abeta oligomers. Neuron 77:929_ 941. CrossRef Medline

Llorens-Martín M, Tejeda GS, Trejo JL (2010) Differential regulation of the variations induced by environmental richness in adult neurogenesis as a function of time: a dual birthdating analysis. PLoS One 5:e12188. CrossRef Medline

Madsen TM, Newton SS, Eaton ME, Russell DS, Duman RS (2003) Chronic electroconvulsive seizure up-regulates beta-catenin expression in rat hippocampus: role in adult neurogenesis. Biol Psychiatry 54:1006-1014. CrossRef Medline

McAvoy KM, Scobie KN, Berger S, Russo C, Guo N, Decharatanachart P, Vega-Ramirez H, Miake-Lye S, Whalen $M$, Nelson M, Bergami M, Bartsch D, Hen R, Berninger B, Sahay A (2016) Modulating neuronal competition dynamics in the dentate gyrus to rejuvenate aging memory circuits. Neuron 91:1356-1373. CrossRef Medline

Miao C, Cao Q, Ito HT, Yamahachi H, Witter MP, Moser MB, Moser EI (2015) Hippocampal Remapping after Partial Inactivation of the Medial Entorhinal Cortex. Neuron 88:590-603. CrossRef Medline

Mignone JL, Kukekov V, Chiang AS, Steindler D, Enikolopov G (2004) Neural stem and progenitor cells in nestin-GFP transgenic mice. J Comp Neurol 469:311-324. CrossRef Medline

Moser MB, Moser EI (1998) Functional differentiation in the hippocampus. Hippocampus 8:608-619. CrossRef Medline

Mukamel EA, Nimmerjahn A, Schnitzer MJ (2009) Automated analysis of cellular signals from large-scale calcium imaging data. Neuron 63:747760. CrossRef Medline

Nilsson M, Perfilieva E, Johansson U, Orwar O, Eriksson PS (1999) Enriched environment increases neurogenesis in the adult rat dentate gyrus and improves spatial memory. J Neurobiol 39:569-578. CrossRef Medline

O'Keefe J, Burgess N (1996) Geometric determinants of the place fields of hippocampal neurons. Nature 381:425-428. CrossRef Medline

Olson AK, Eadie BD, Ernst C, Christie BR (2006) Environmental enrichment and voluntary exercise massively increase neurogenesis in the adult hippocampus via dissociable pathways. Hippocampus 16:250260. CrossRef Medline

Parent JM, Elliott RC, Pleasure SJ, Barbaro NM, Lowenstein DH (2006) Aberrant seizure-induced neurogenesis in experimental temporal lobe epilepsy. Ann Neurol 59:81-91. CrossRef Medline

Pilz GA, Carta S, Stäuble A, Ayaz A, Jessberger S, Helmchen F (2016) Functional imaging of dentate granule cells in the adult mouse hippocampus. J Neurosci 36:7407-7414. CrossRef Medline

Rhee S, Kirschen GW, Gu Y, Ge S (2016) Depletion of primary cilia from mature dentate granule cells impairs hippocampus-dependent contextual memory. Sci Rep 6:34370. CrossRef Medline

Rossi C, Angelucci A, Costantin L, Braschi C, Mazzantini M, Babbini F, Fabbri ME, Tessarollo L, Maffei L, Berardi N, Caleo M (2006) Brainderived neurotrophic factor (BDNF) is required for the enhancement of hippocampal neurogenesis following environmental enrichment. Eur J Neurosci 24:1850-1856. CrossRef Medline

Sahay A, Scobie KN, Hill AS, O'Carroll CM, Kheirbek MA, Burghardt NS, Fenton AA, Dranovsky A, Hen R (2011a) Increasing adult hippocampal neurogenesis is sufficient to improve pattern separation. Nature 472:466470. CrossRef Medline

Sahay A, Wilson DA, Hen R (2011b) Pattern separation: a common function for new neurons in hippocampus and olfactory bulb. Neuron 70 : 582-588. CrossRef Medline

Saxe MD, Malleret G, Vronskaya S, Mendez I, Garcia AD, Sofroniew MV, Kandel ER, Hen R (2007) Paradoxical influence of hippocampal neurogenesis on working memory. Proc Natl Acad Sci U S A 104:4642-4646. CrossRef Medline

Scharfman HE, Goodman JH, Sollas AL (2000) Granule-like neurons at the hilar/CA3 border after status epilepticus and their synchrony with area CA3 pyramidal cells: functional implications of seizure-induced neurogenesis. J Neurosci 20:6144-6158. Medline

Sierra A, Martín-Suárez S, Valcárcel-Martín R, Pascual-Brazo J, Aelvoet SA, Abiega O, Deudero JJ, Brewster AL, Bernales I, Anderson AE, Baekelandt V, Maletić-Savatić M, Encinas JM (2015) Neuronal hyperactivity accel- 
erates depletion of neural stem cells and impairs hippocampal neurogenesis. Cell Stem Cell 16:488-503. CrossRef Medline

Song J, Zhong C, Bonaguidi MA, Sun GJ, Hsu D, Gu Y, Meletis K, Huang ZJ, Ge S, Enikolopov G, Deisseroth K, Luscher B, Christian KM, Ming GL, Song H (2012) Neuronal circuitry mechanism regulating adult quiescent neural stem-cell fate decision. Nature 489:150-154. CrossRef Medline

Song J, Sun J, Moss J, Wen Z, Sun GJ, Hsu D, Zhong C, Davoudi H, Christian KM, Toni N, Ming GL, Song H (2013) Parvalbumin interneurons mediate neuronal circuitry-neurogenesis coupling in the adult hippocampus. Nat Neurosci 16:1728-1730. CrossRef Medline

Stone SS, Teixeira CM, Devito LM, Zaslavsky K, Josselyn SA, Lozano AM, Frankland PW (2011) Stimulation of entorhinal cortex promotes adult neurogenesis and facilitates spatial memory. J Neurosci 31:13469-13484. CrossRef Medline

Sun GJ, Zhou Y, Stadel RP, Moss J, Yong JH, Ito S, Kawasaki NK, Phan AT, Oh JH, Modak N, Reed RR, Toni N, Song H, Ming GL (2015) Tangential migration of neuronal precursors of glutamatergic neurons in the adult mammalian brain. Proc Natl Acad Sci U S A 112:9484-9489. CrossRef Medline

Tashiro A, Makino H, Gage FH (2007) Experience-specific functional mod- ification of the dentate gyrus through adult neurogenesis: a critical period during an immature stage. J Neurosci 27:3252-3259. CrossRef Medline

Temprana SG, Mongiat LA, Yang SM, Trinchero MF, Alvarez DD, Kropff E, Giacomini D, Beltramone N, Lanuza GM, Schinder AF (2015) Delayed coupling to feedback inhibition during a critical period for the integration of adult-born granule cells. Neuron 85:116-130. CrossRef Medline

van Ooyen A, Butz-Ostendorf M (2017) The rewiring brain: a computational approach to structural plasticity in the adult brain. New York: Elsevier Science.

van Praag H, Kempermann G, Gage FH (2000) Neural consequences of environmental enrichment. Nat Rev Neurosci 1:191-198. Medline

Williams BM, Luo Y, Ward C, Redd K, Gibson R, Kuczaj SA, McCoy JG (2001) Environmental enrichment: effects on spatial memory and hippocampal CREB immunoreactivity. Physiol Behav 73:649-658. CrossRef Medline

Xiu J, Zhang Q, Zhou T, Zhou TT, Chen Y, Hu H (2014) Visualizing an emotional valence map in the limbic forebrain by TAI-FISH. Nat Neurosci 17:1552-1559. CrossRef Medline

Zhao C, Deng W, Gage FH (2008) Mechanisms and functional implications of adult neurogenesis. Cell 132:645-660. CrossRef Medline 